\title{
دور فريضة الزكاة في الاقتصاد الاسلامي في معالجة ظاهرة التضخم الركودي
}

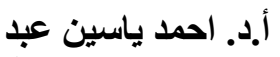

كلية الادارة والاقتصاد_الجامعة العراقية لئ ahmedyassin207@gmail.com
د. حسن خلف راضي جامعة دجلة الأهلية Hassan.kalf@duc.edu.iq

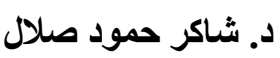

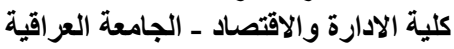
Shakir.sallal@aliraqia.edu.iq

|لماخص

تعد مشكلة التضخم الركودي من اصعب المشكلات الاقتصادية التي واجهت الاقتصاد الر أسمالي كونها جاءت خلاف توقعات الاقتصاديين حول العلاقة بين التضخم والبطالة، ففي الوقت الذي ساد فيه الاعتقاد أن هناك علاقة عكسية بين التضخم و البطالة، ظهرت في عقد السبعينيات مشكلة التضخم الركودي و المتمنلة بوجود التضخم مع ارتفاع معدلات البطالة مما جعل البلدان تعاني من الركود الاقتصادي الأمر الذي ادى الى ظهور آراء لمدارس لرد اقتصادية مختلفة لإيجاد الحلول لهذه المشكلة. وهذا البحث يظهر دور الزكاة كإحدى ادوات السياسة المالية الاسلامية في معالجة هذه الظاهرة اذا ما علمنا انها من القروض المالية الدورية الاجبارية في الاقتصاد الاسلامي، كما أن انفاق حصيلة الزكاة يخضع لسلطة

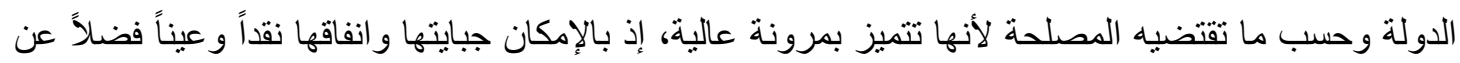

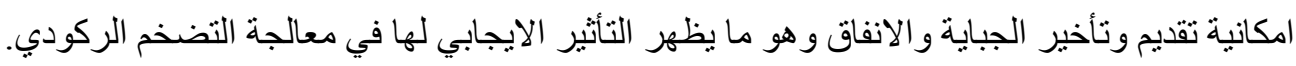
الكلمات المفتاحية: الزكاة، الاقتصاد الاسلامي، التضخم الركودي. 


\title{
المجلة الحولية اللملوم الآسانية والإمتماعية
} International Journal of Humanities and Social Sciences

website:www.ijohss.com

Email:editor@ijohss.com

أغسطس 2020

العدد (14)

ISSN: $2415-4822$

Volume (14) August 2020

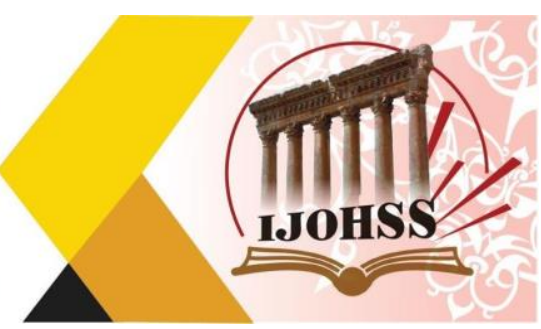

\section{The Role of Zakat in the Islamic Economy in Addressing Recessionary Inflation}

\author{
Dr. Shaker Hammoud Salal \\ College of Administration and Economics - Iraqi University \\ Shakir.sallal@aliraqia.edu.iq \\ Dr. Hassan Khalaf Radhy \\ Dijlah University \\ Hassan.kalf@duc.edu.iq \\ Prof.Dr. Ahmed Yassin Abd \\ College of Administration and Economics - Iraqi University \\ ahmedyassin207@gmail.com
}

\begin{abstract}
The problem of stagnant inflation is one of the most difficult economic problems that the capitalist economy faced, as it came contrary to economists 'expectations about the relationship between inflation and unemployment. Unemployment, which made countries suffer from economic recession, which led to the emergence of opinions of different economic schools to find solutions to this problem.

This research shows the role of Zakat as one of the tools of Islamic financial policy in dealing with this phenomenon if we know that it is one of the compulsory periodic financial loans in the Islamic economy, just as the spending of Zakat proceeds is subject to the authority of the state and as required by the interest because it is characterized by high flexibility, as it can be collected and spent in cash and in kind In addition to the possibility of providing and delaying levy and spending, which shows its positive effect in dealing with recessionary inflation.
\end{abstract}

Keywords: Zakat, Islamic economics, stagnant inflation. 


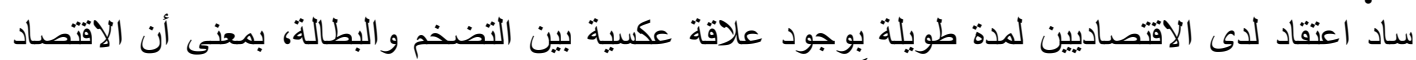

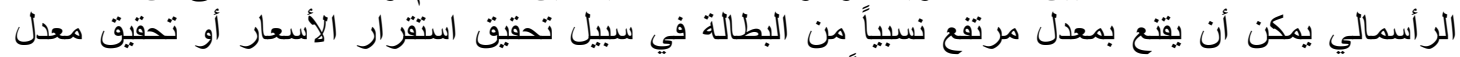

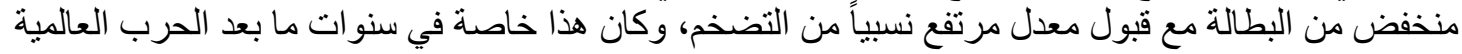

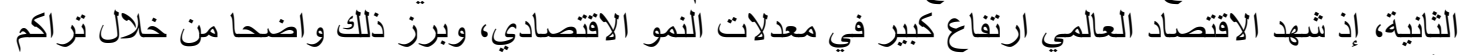

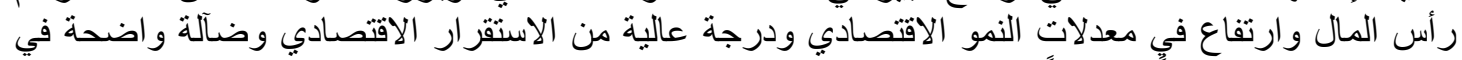

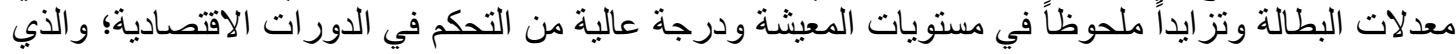

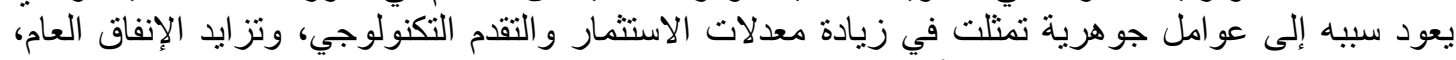

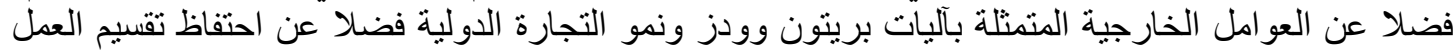
الدولي بنمطه لصالح البلدان المتقدمة.

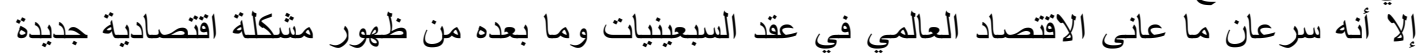

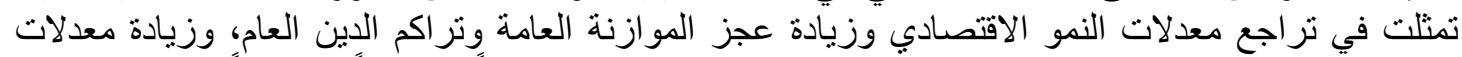

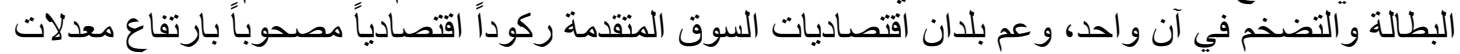

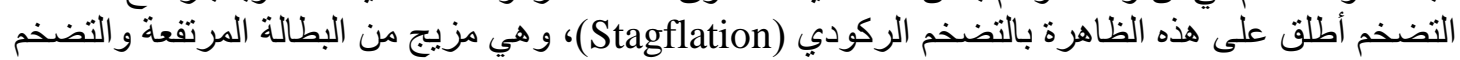

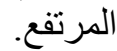
وفي ظل مشكلة التضخم الركودي يلاحظ أن الاقتصاد الاسلامي يمتلك العديد من ادوات العات السياسة المالية و التي

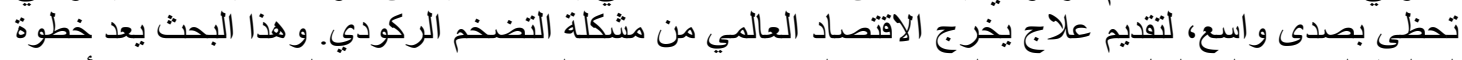

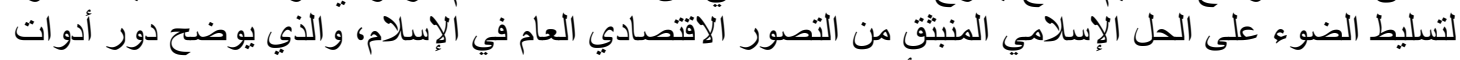

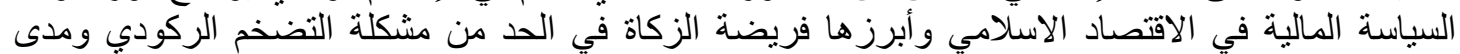
مساهمتها في تحقيق الاستقر ار الاقتصادي الادي والمادي المالي.

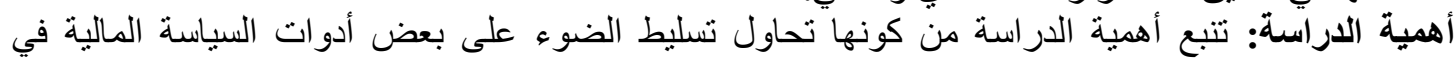

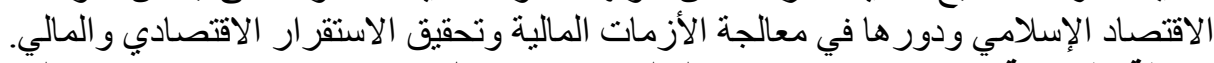

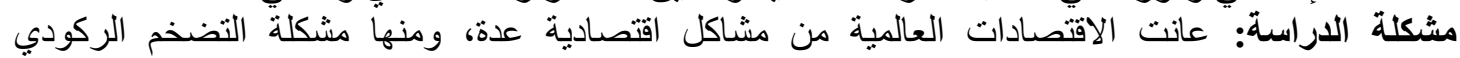
(Stagflation)

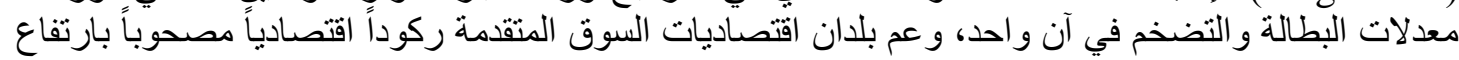

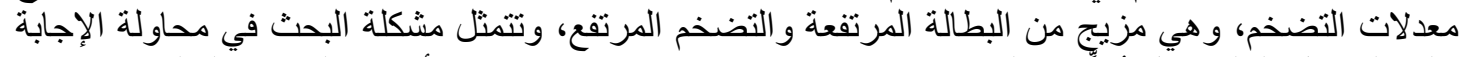

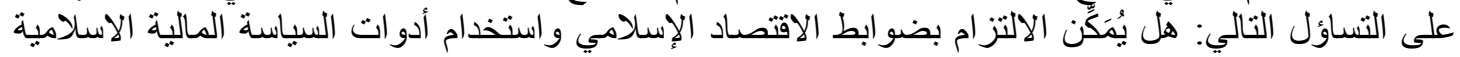

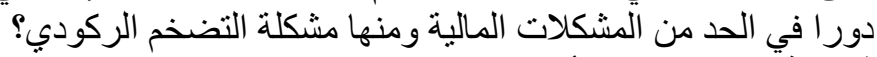

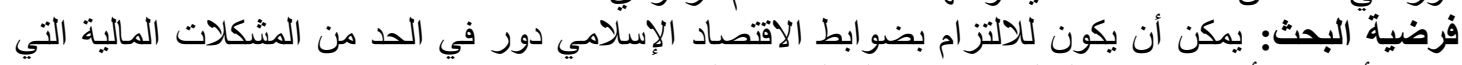

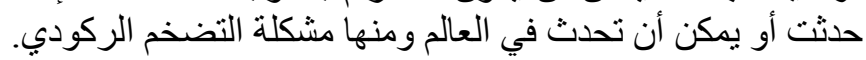

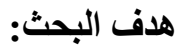
1. التأصيل النظري لأبرز المدارس الفكرية والنظريات التي تناولت مشكلة التضخم الركودي.

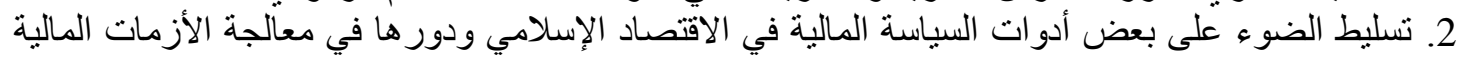

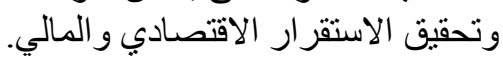
3. الكثف عن مدى فاعلية فريضة الزئن كاة في الاقتصاد الاسلامي في معالجة مشكلة التضخم الركودي.

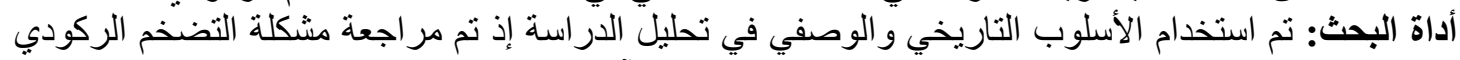

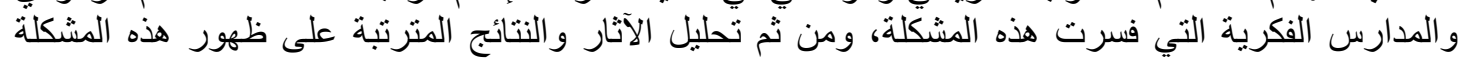

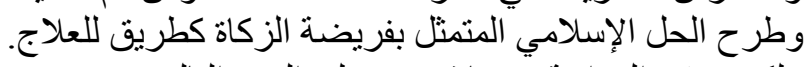

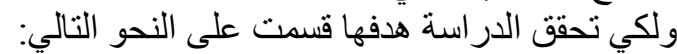

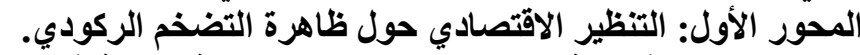

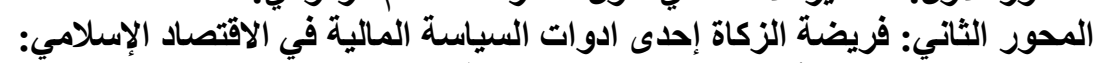

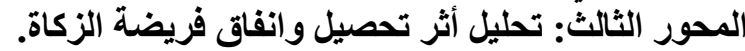
المحور الأول: التنظير الاقتصادي حولئ تول تفسير ظاهرة التضخم الركودي: 
المجلة اللحولية اللملوم الآسانية والإمتماعية International Journal of Humanities and Social Sciences

website:www.ijohss.com

Email:editor@ijohss.com

ISSN: 2415 - 4822

\author{
أغسطس 2020 \\ Volume (14) August 2020
}

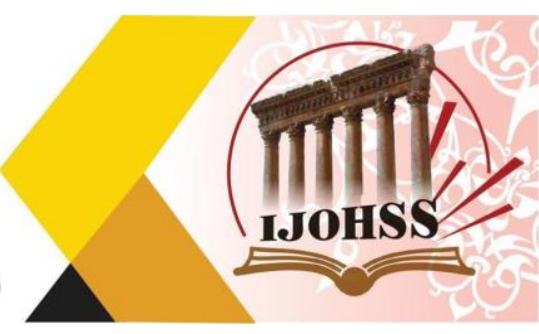

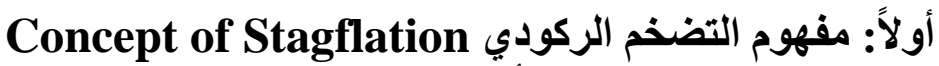

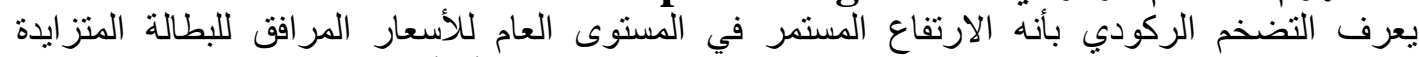

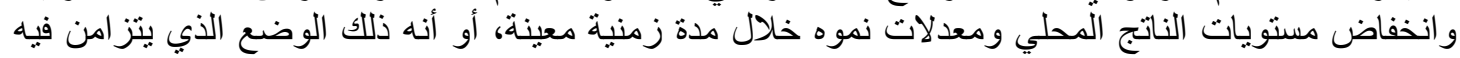

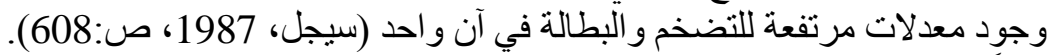

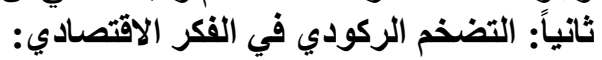

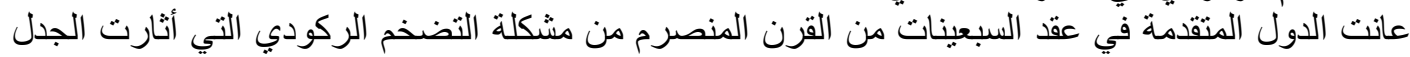

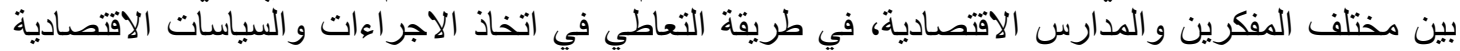

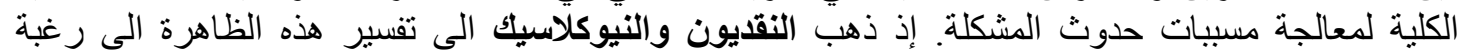

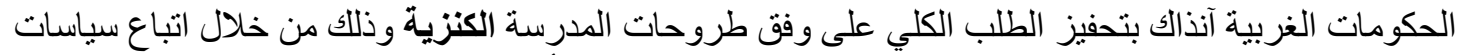

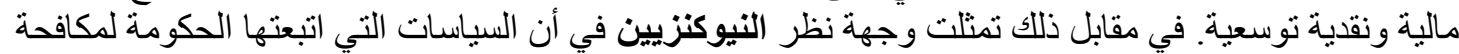

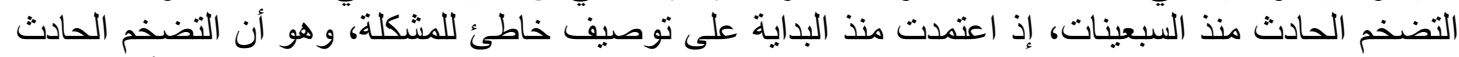

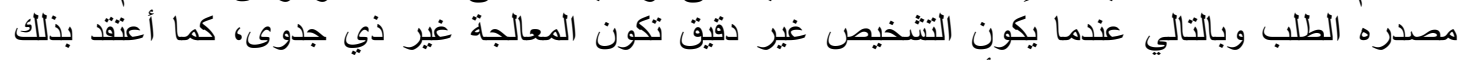

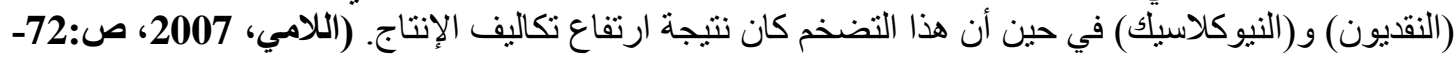

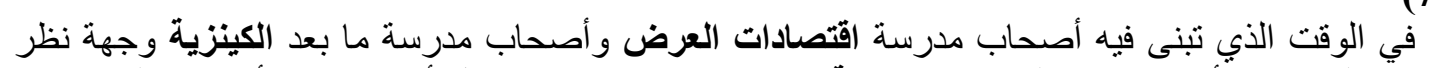

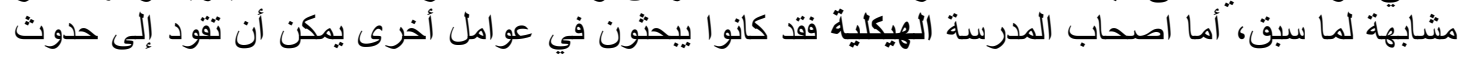

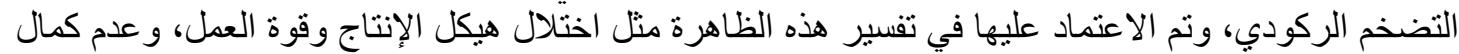

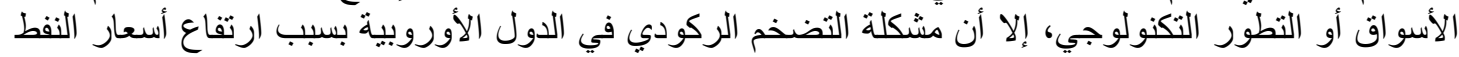

الخام في تللك الفترة (Norbert,2012, p:2-12).

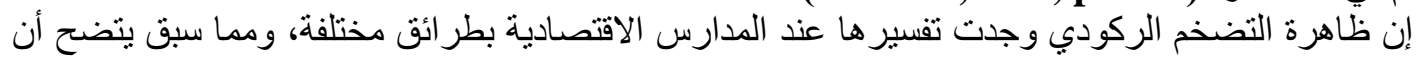

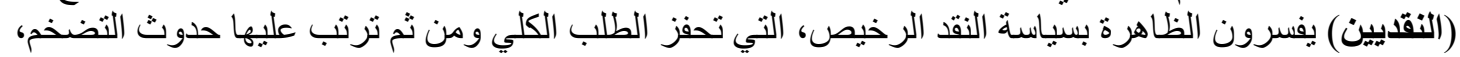

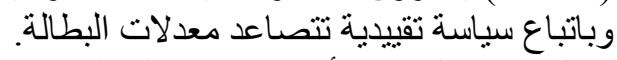

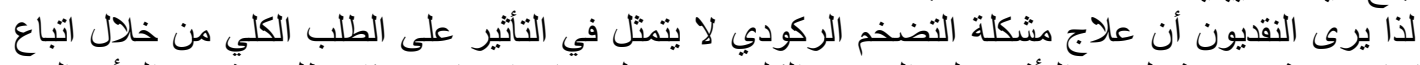

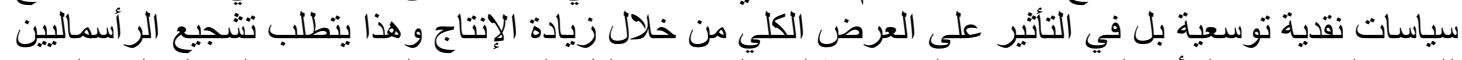

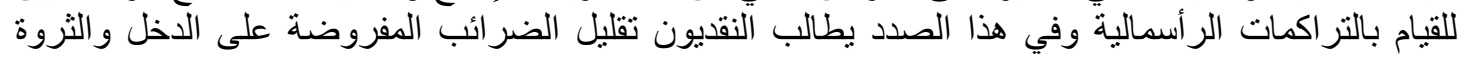

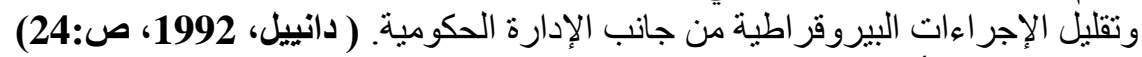

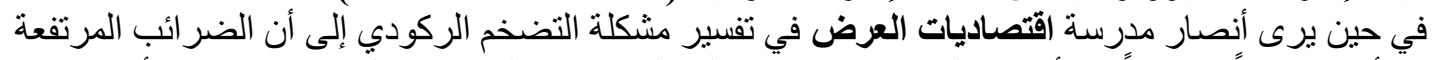

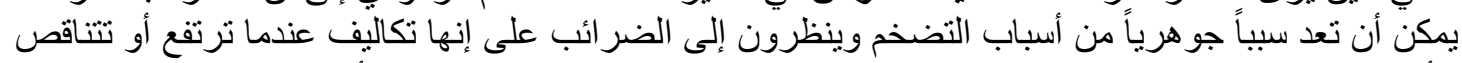

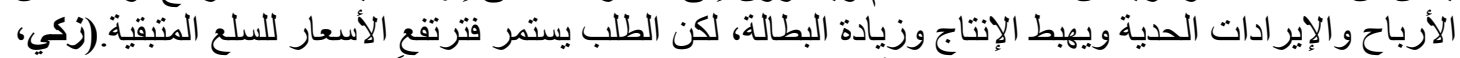

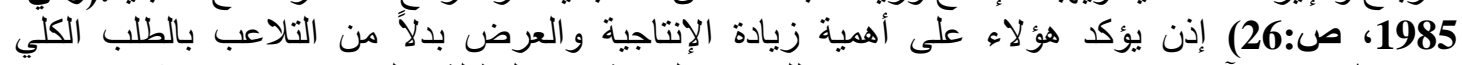

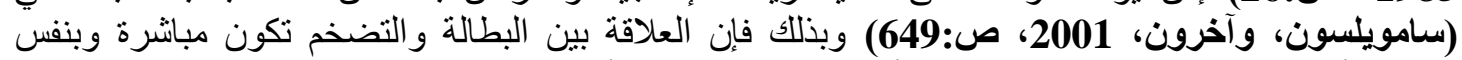

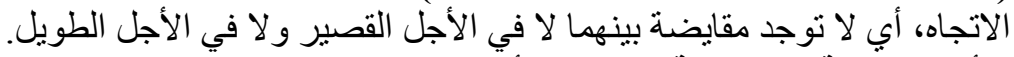

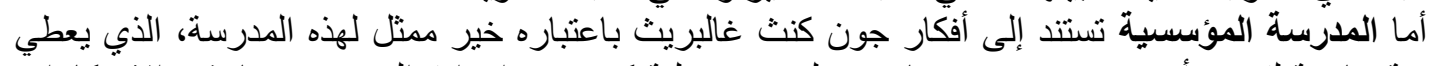

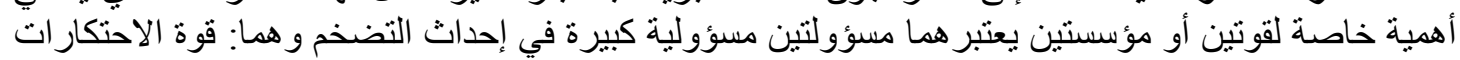

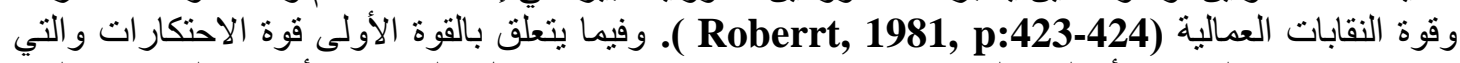

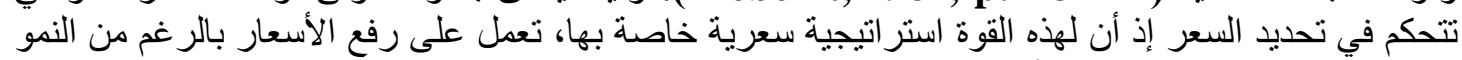

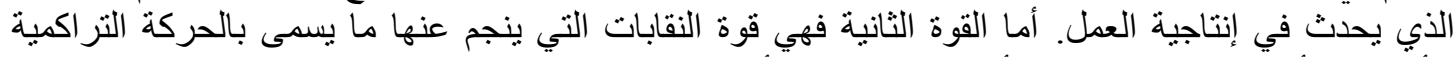

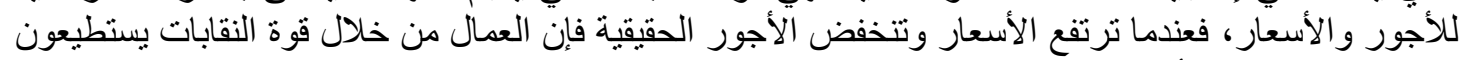

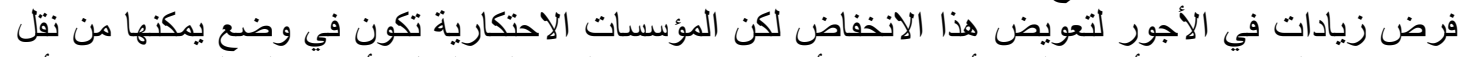

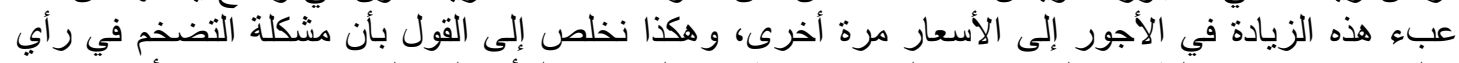

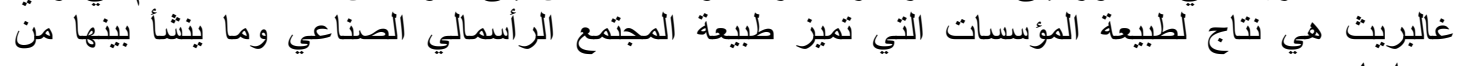

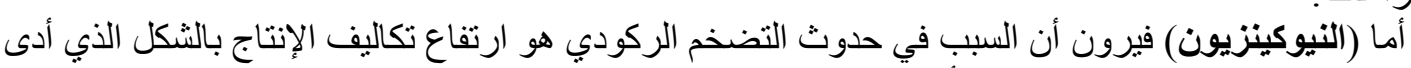

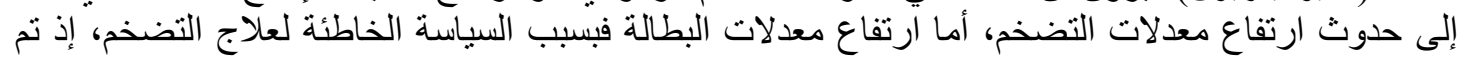


أغسطس 2020

(14) (لعدا

ISSN: $2415-4822$

Volume (14) August 2020

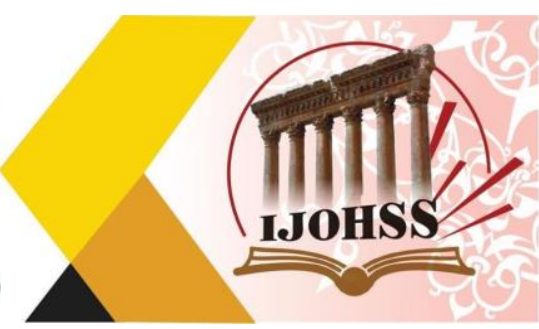

اتباع سياسه نقدية تقييدية لمعالجة التضخم الذي يعتقد انه تضخم طلب، وكان تأثثر ها سلبياً على الاستثمار

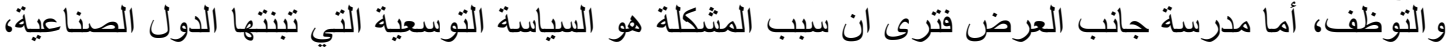

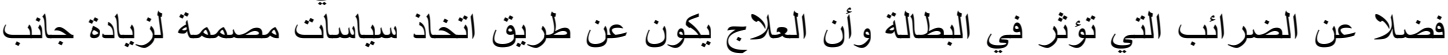
العرض الكلي من السلع و الخدمات.

بصورة عامة معظم المدارس الاقتصادية باستثناء (الهيكلين) يرون أن سبب حدوث البـاث الظاهرة هي أنها تبدأ

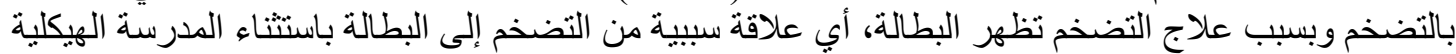
التي نرى أن التضخم مشكلة لها أسبابها المختلفة عن مشكلة البطالة.

المحور الثاني: فريضة الزكاة إحدى ادوات السياسة المالية في الاقتصاد الإسلامي

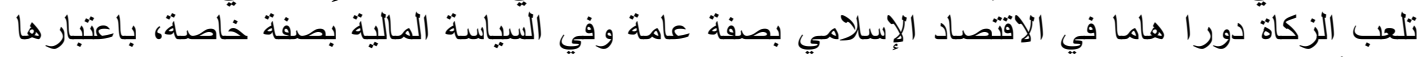

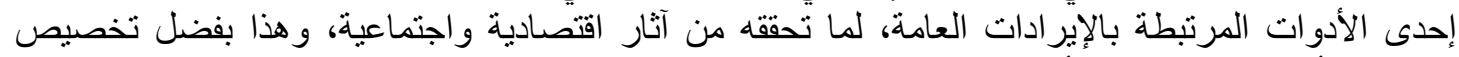

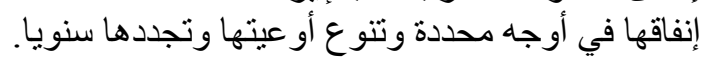

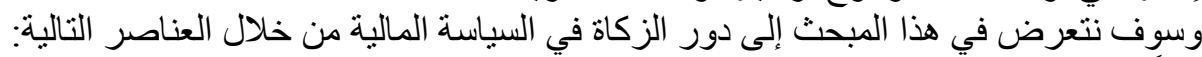

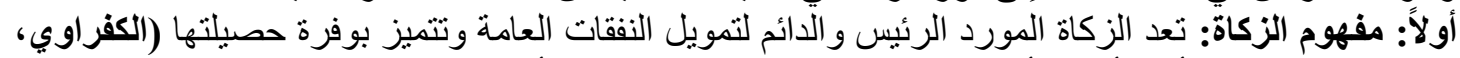

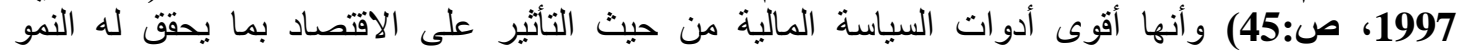

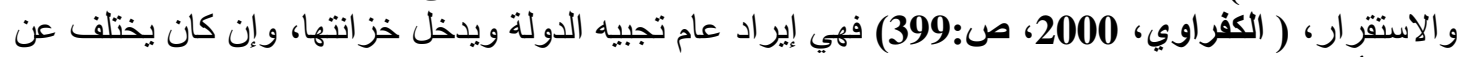

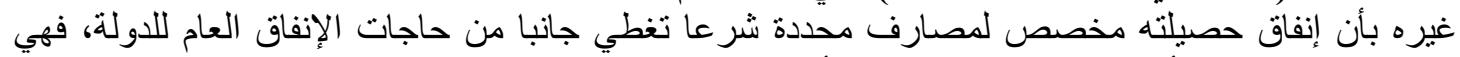
تشمل بصورة خاصنة إنفاق أنواع الضمان الاجتماعي بأنثكاله المختلفة.

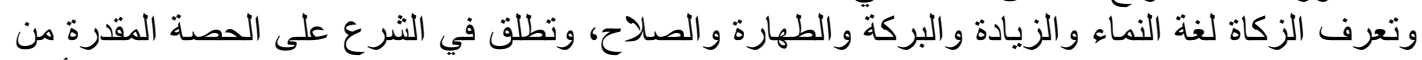

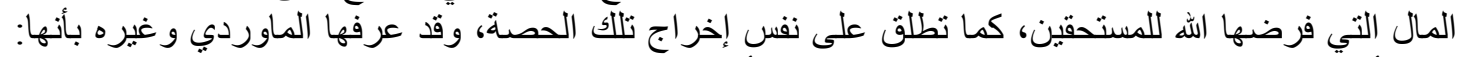

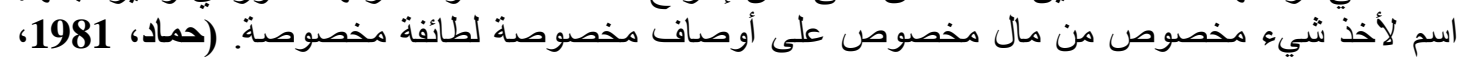

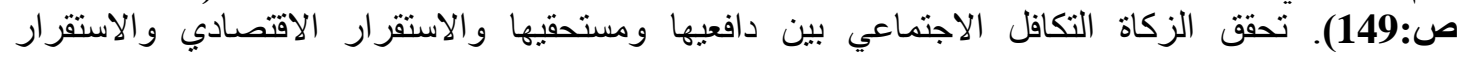
الاجتماعي و السياسي.

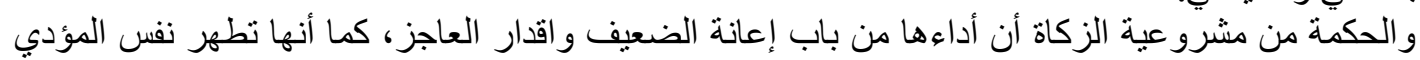

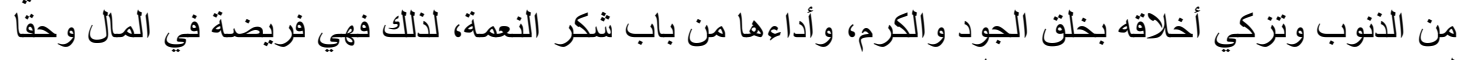

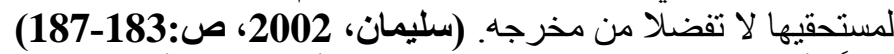

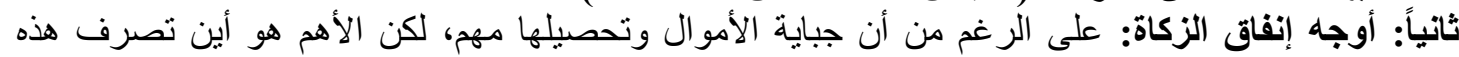

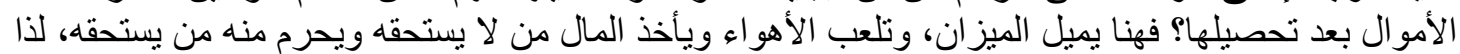

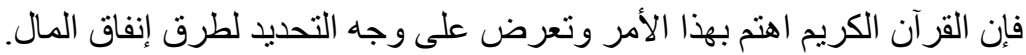

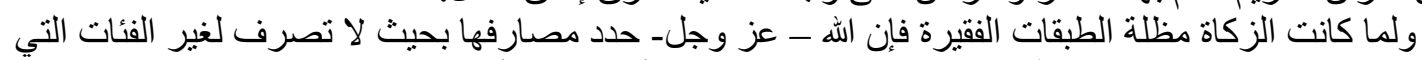

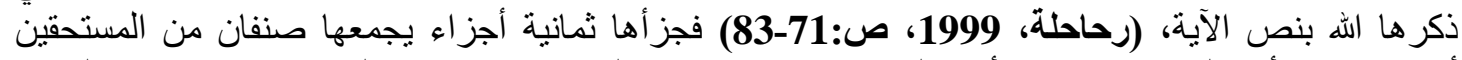

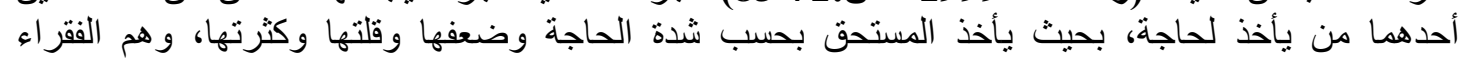

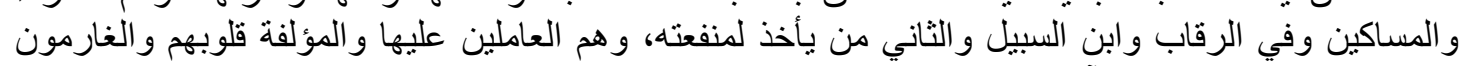

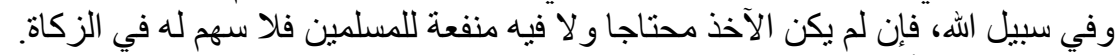

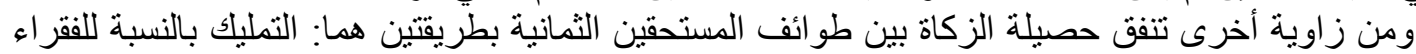

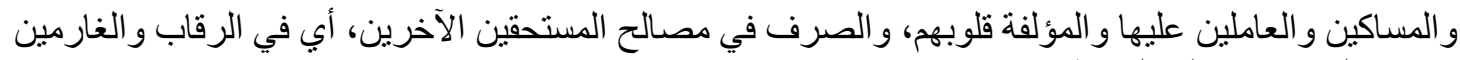

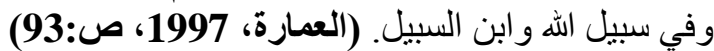

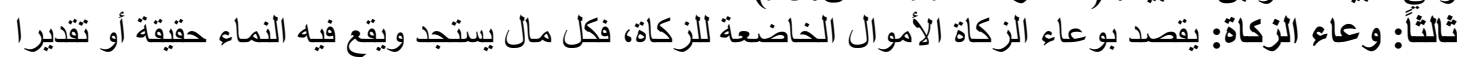

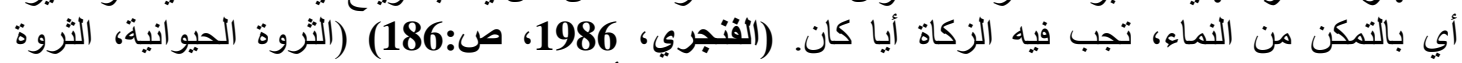

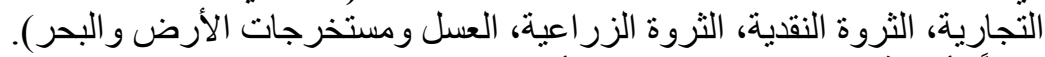

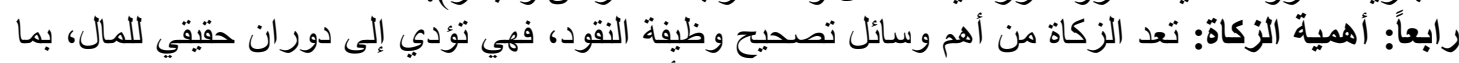

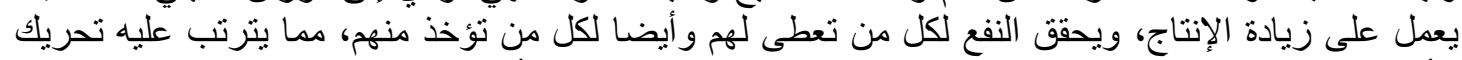

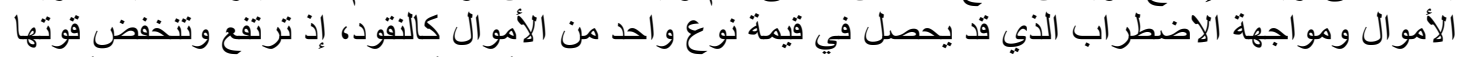

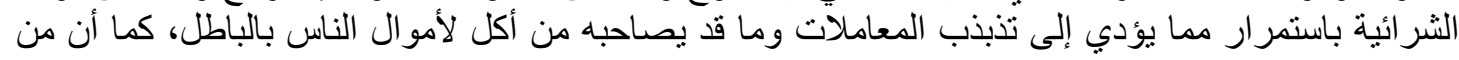




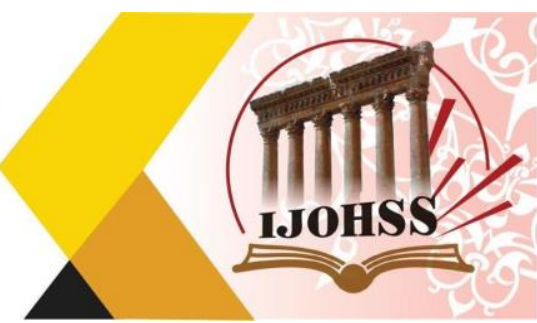

يأخذون الزكاة ينفقونها مباثرة ومن ثم تأخذ سبيلها الصحيح نحو تحريك الموارد البشرية أيضا إلى جانب تحريك

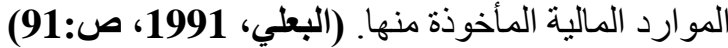

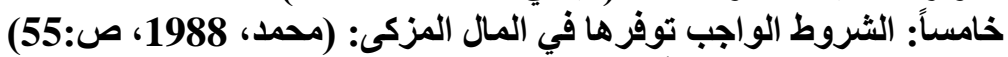

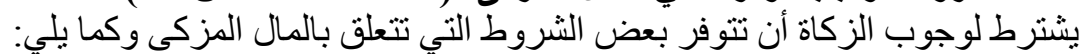

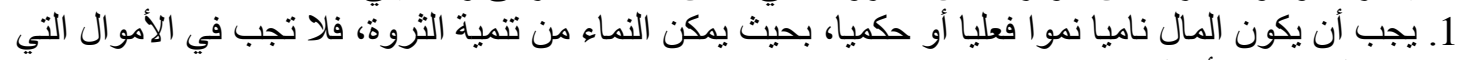

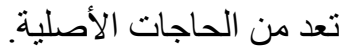
2. أن يكون المال مملوكا ملكا تاما، إذ تدفع الزكاة عن المال الذي لم يخرج من يد صاحبه، أو المال الذي أودعه

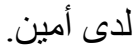

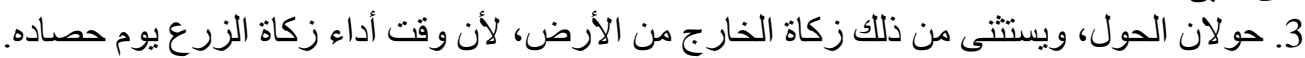

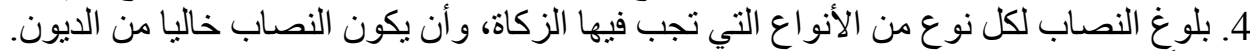
سادساً: دور فريضة الزكاة في السياسة التمالية الإسلامية الناكية

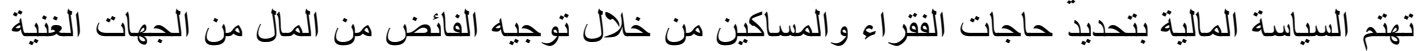

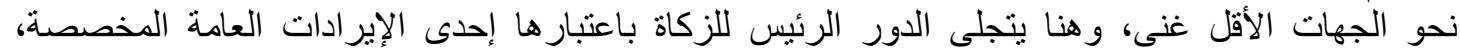

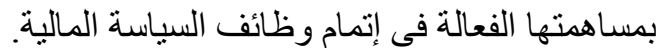

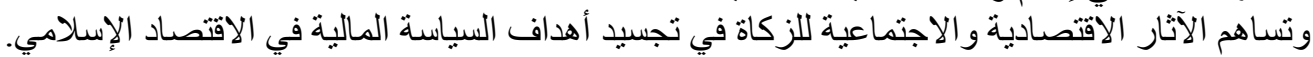

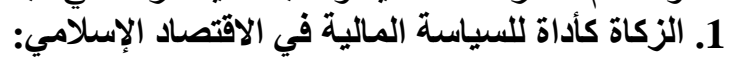

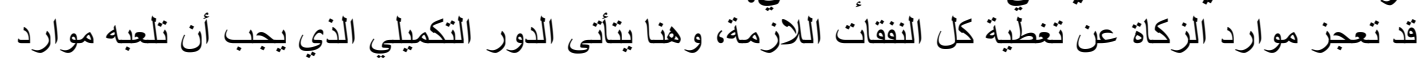

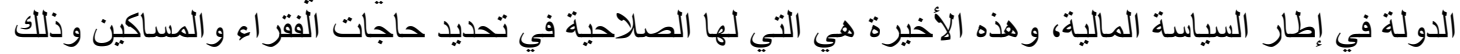

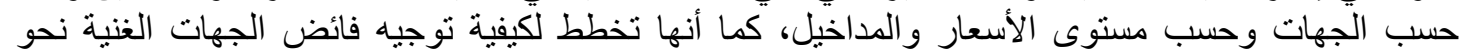

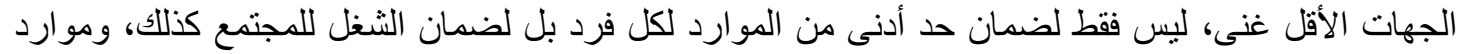

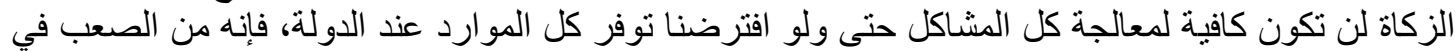

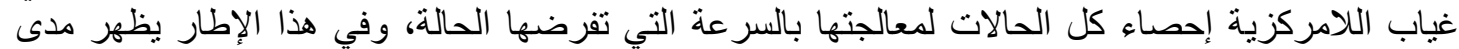

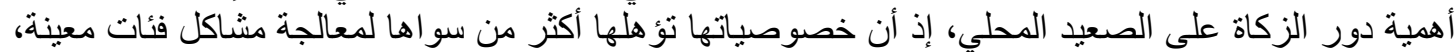

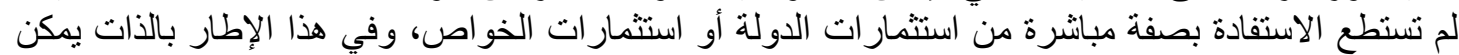

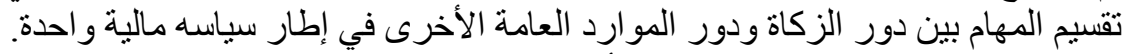

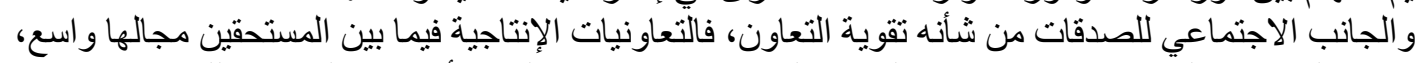

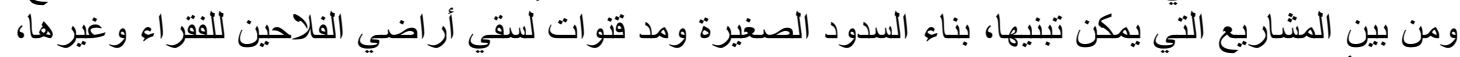

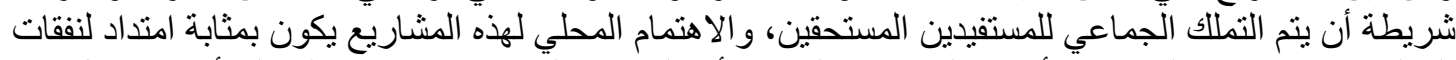

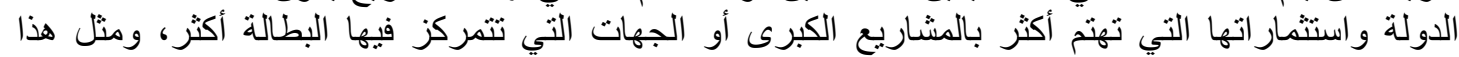

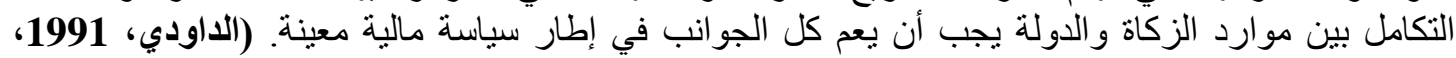

ص:508:

فبافتر اض أن الدولة تقوم بمسؤولياتها في تنظيم شؤون الزكاة جباية وصرفا، فإن لحون لحصيلة الزكاة دورا هاما

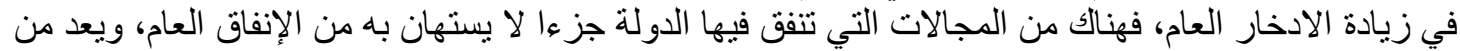

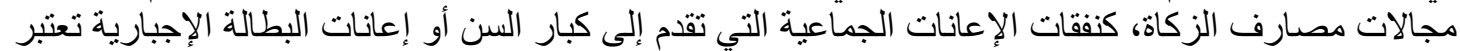

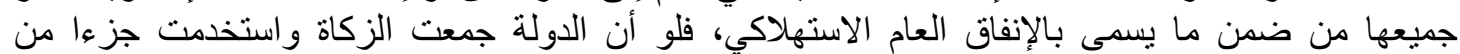

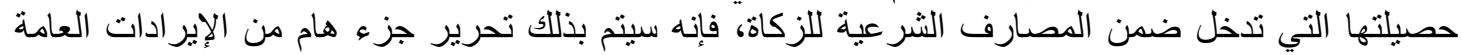
يمكن استخدامه في الإنفاق العام الاستثماري.

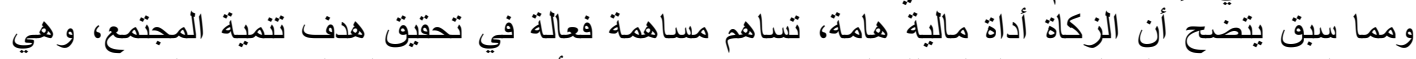

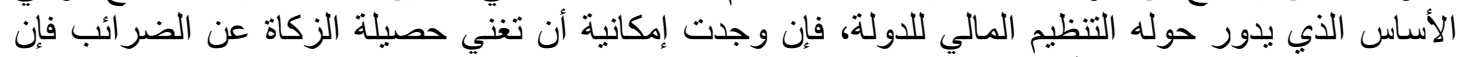
الضر ائب لا تغني عن الزكاة أبدا. (الطاهر، 1989، ص:268-278) 
المجلة اللحولية اللملوم الآسانية والإمتماعية International Journal of Humanities and Social Sciences

website:www.ijohss.com

Email:editor@ijohss.com

ISSN: $2415-4822$
أغسطس 2020

Volume (14) August 2020

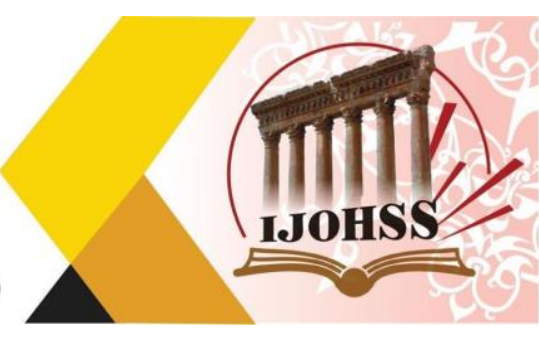

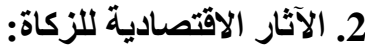

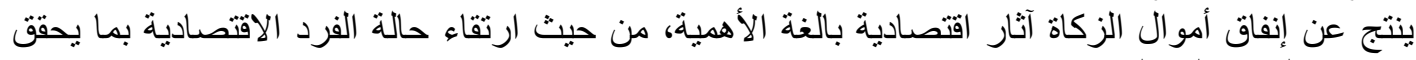

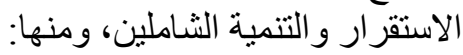

أ. إعادة توزيع الاخل والته والثروة:

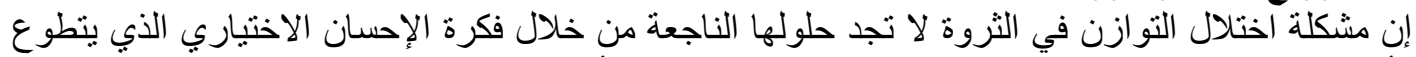

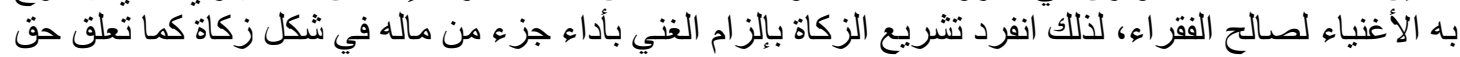

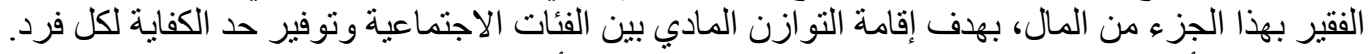

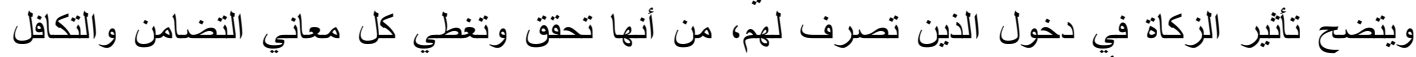
الاجتماعيين، فضلا على أنها دخلا مناسبا يسمح بمو اصلة النشاط الاقتصادي لمستحقيها. (الكفراوي، 2000،

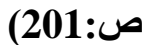

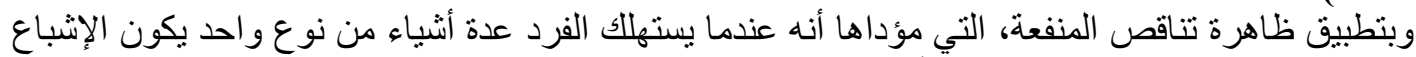

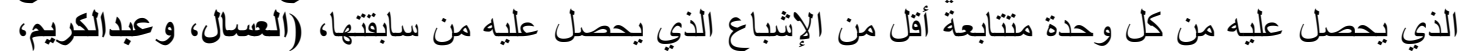

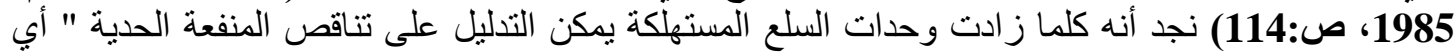

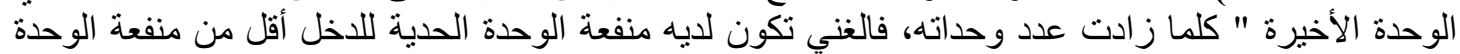

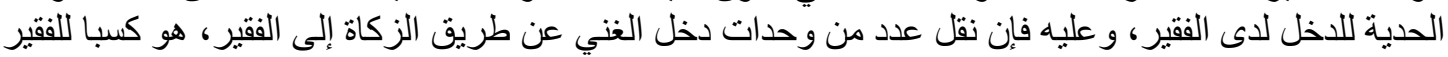

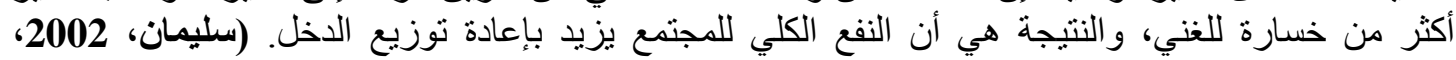

ص:209)

ذللك أن الزكاة لا تخرج إلا بعد بلوغ النصاب أب من الفائض عن الحاجيات الأصلية و الضرورية للمكلف،

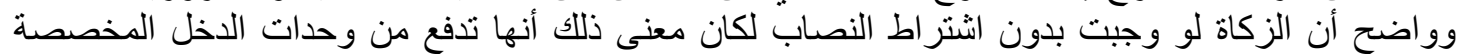

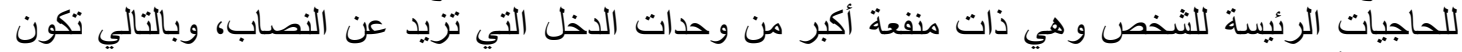

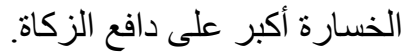

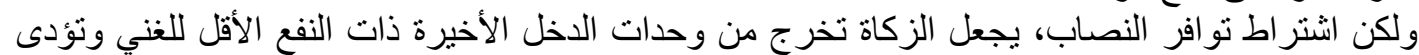

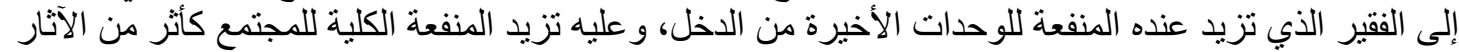
التوزيعية للزكاة.

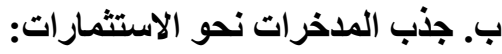

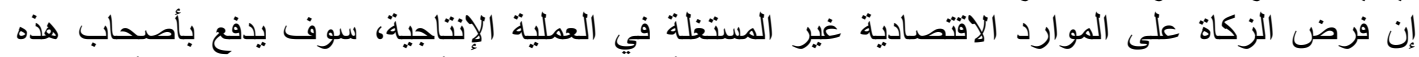

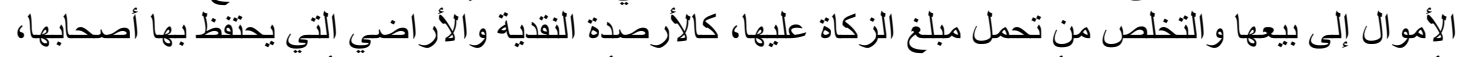

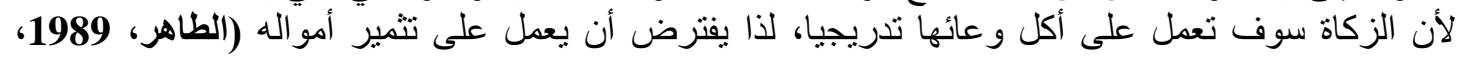

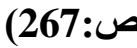

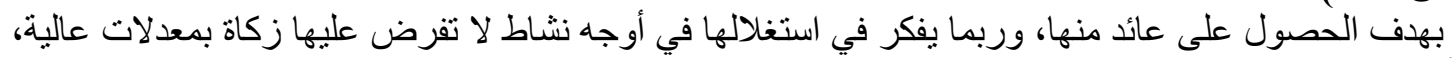

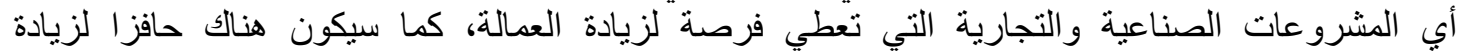
الأستثمار ات رغم انخفاض العائد، طالما أنهاً تحقق ما يكفي لسداد الزكاة والئ والمحافظة على قيمة الأمو ال. (أبو زيد،

وحسين، 1999، ص: ص:

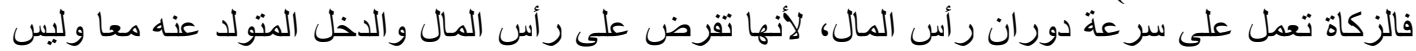

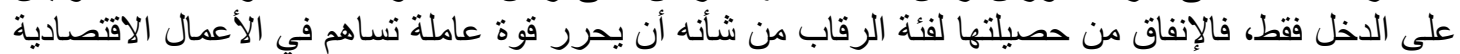

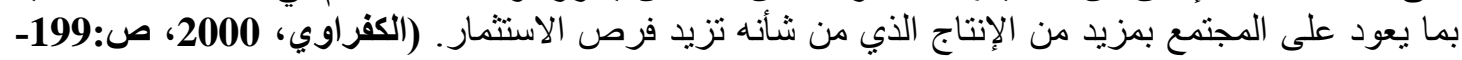

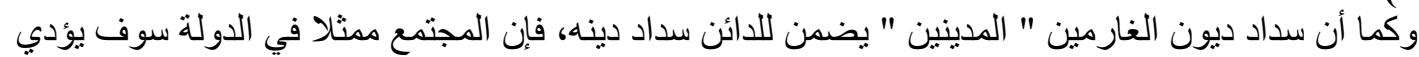

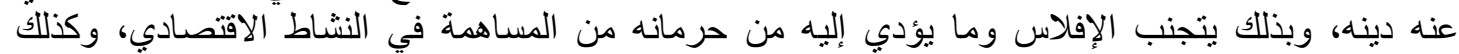

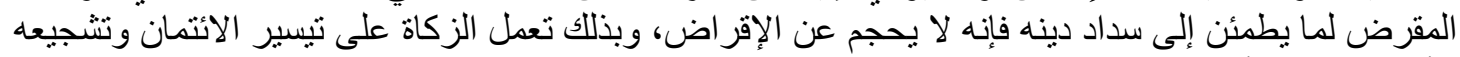

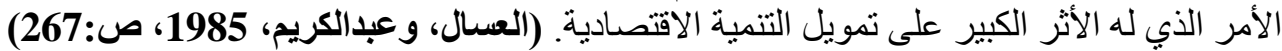

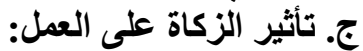

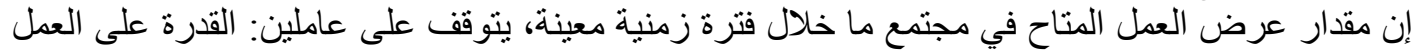
و الرغبة في العمل، فمن جانب القدرة على العمل فإنها تتوقف على على كمية ونو عية العمل المتاح للعملية الإنتاجية، 


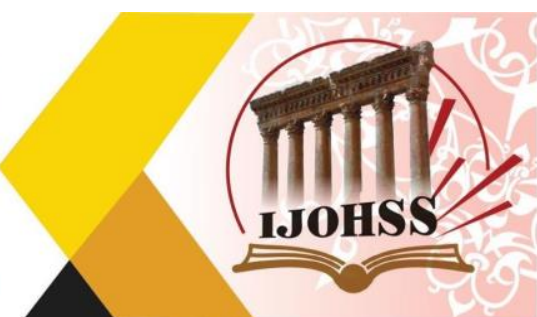

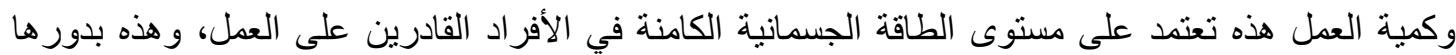

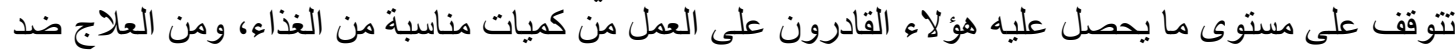

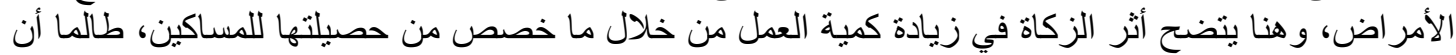
المسكين هو الذي يكون مستوى دخله منخفض ما يجعله ـالمسكين ـقادرا على المحافظة على على كمية العمل

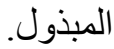

كما يتضح أثرها من زاوية سهمي الغارمين وابن السبيل، ومن أنواع الغارمين التاجر أو أي منتج استدان

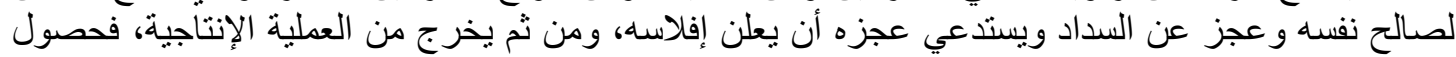

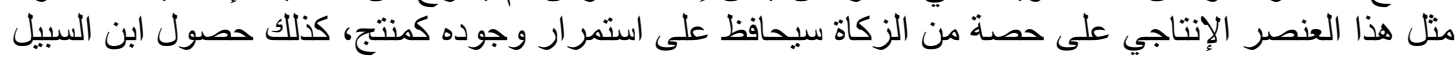

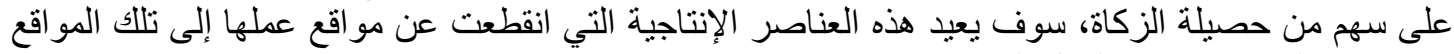
ما يترتب عليه زيادة كمية العمل المتاحة.

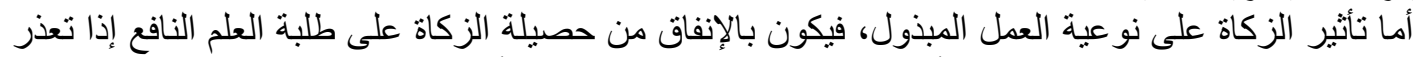

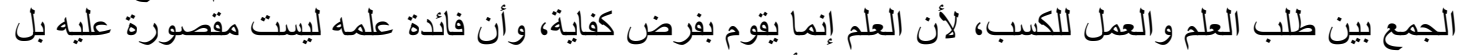

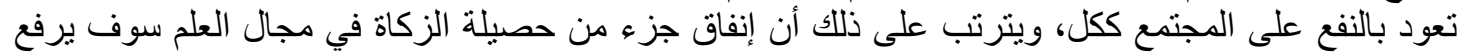

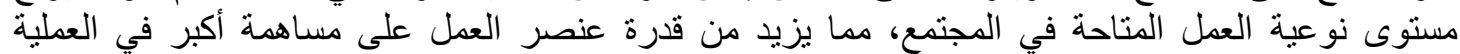

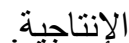

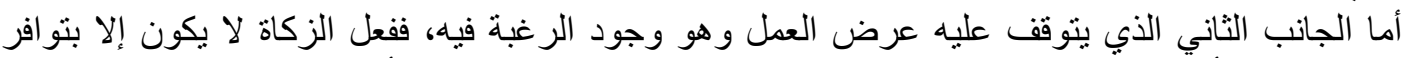

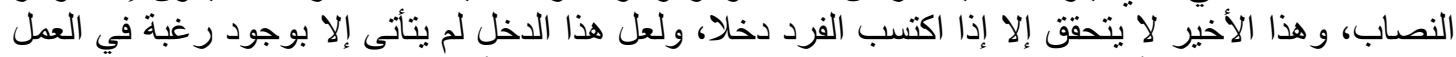

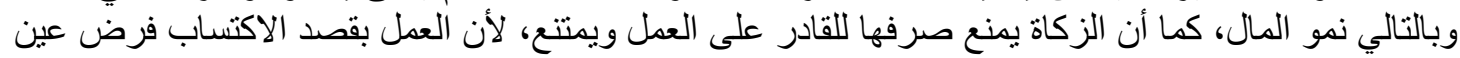

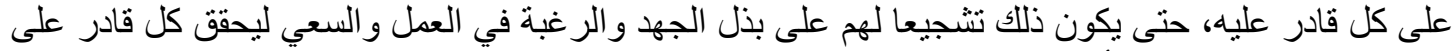

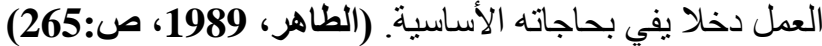

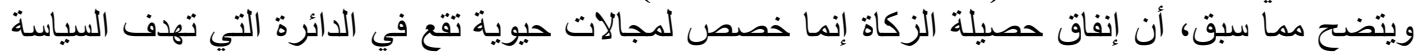
المالية في الاقتصاد الإسلامي التكفل بها، مما يجعل الزكاة تحل محل الإنفاق العام وتلعب دور أداة من أدوات التات التهات

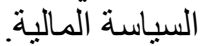

المحور الثالث: تحليل أثر تحصيل وانفاق فريضة الزكاة

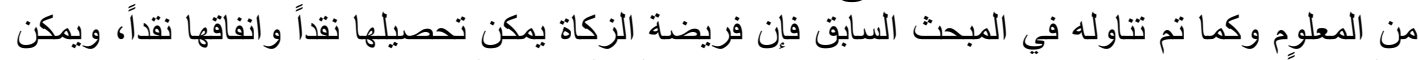

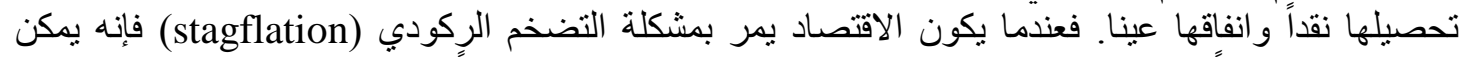

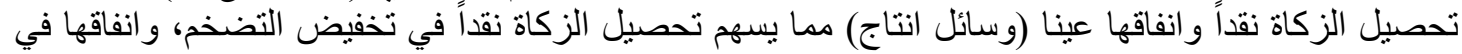

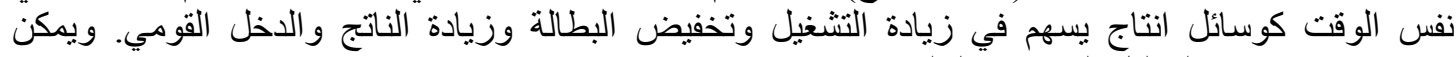
توضيحها باستخدام التحليل البياني وكالتانيالي:

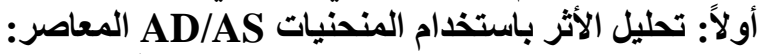

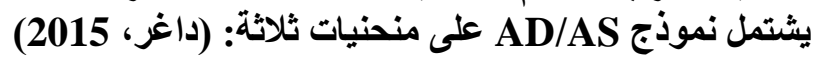

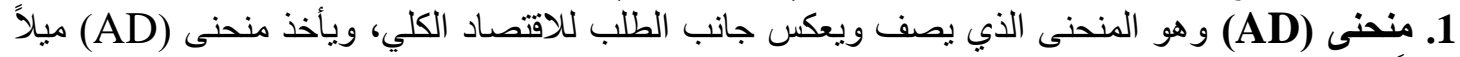

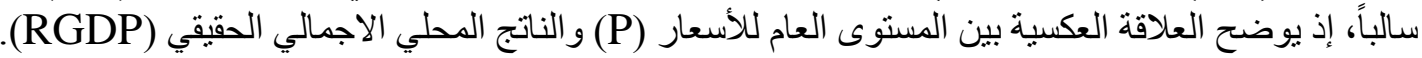

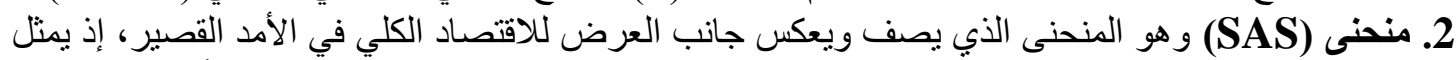

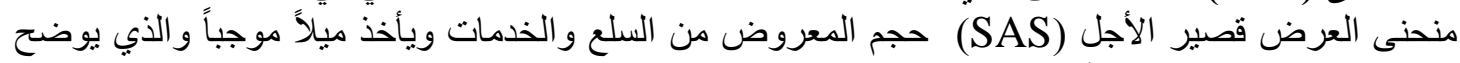

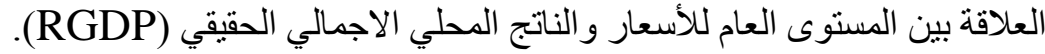

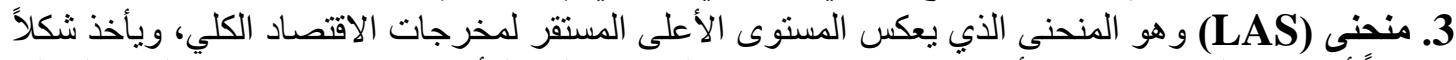

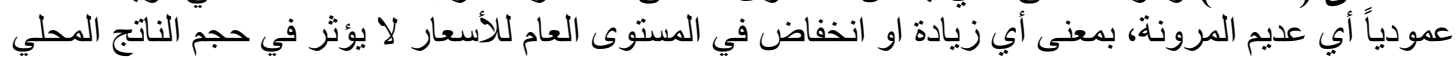

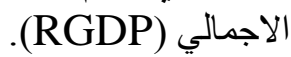
يتحقق التوازن بموجب نموذج (AD/AS) عند تقاطع المنحنيين ليتحقق التوازن عند

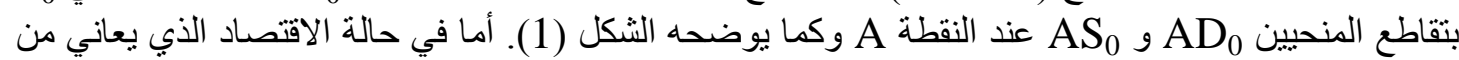

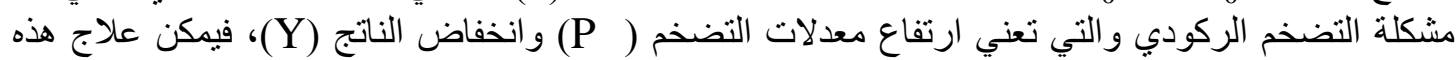




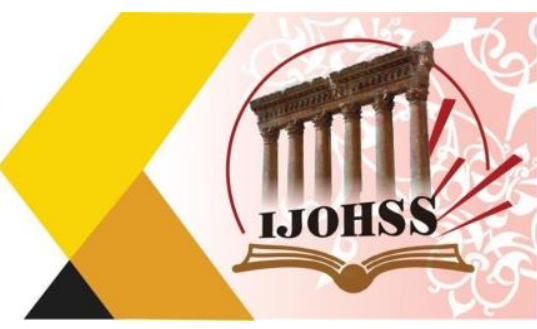

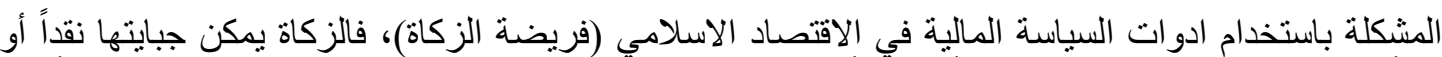

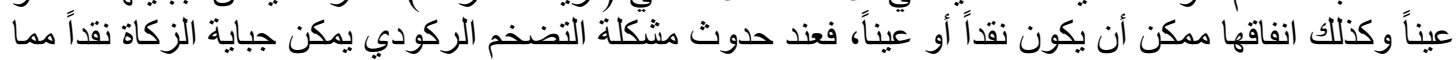
يساعد في نقل منحنى الطلب الكلي (AD منحني

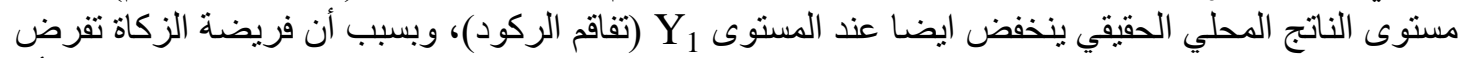

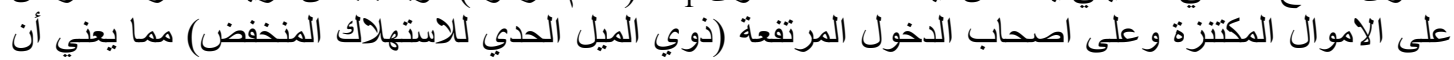

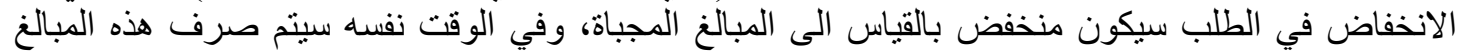

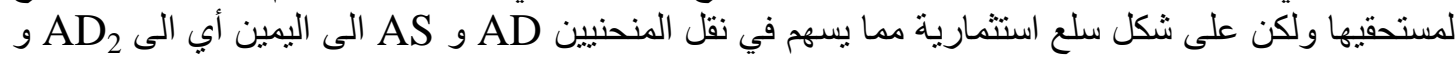

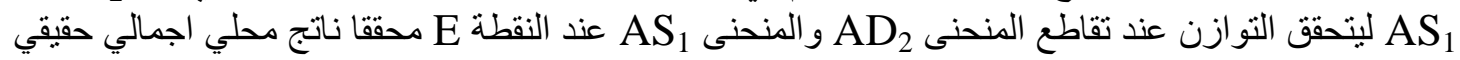

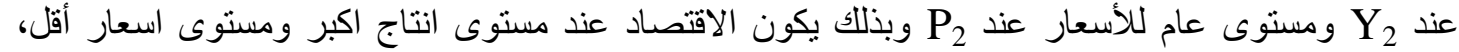
و انتقال منحنى ألت

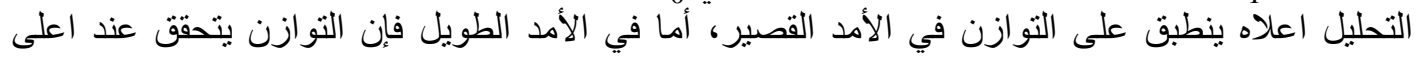

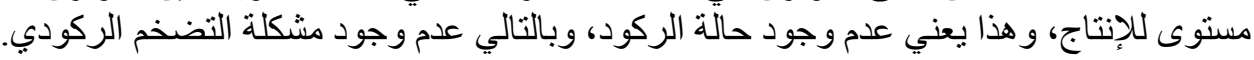
شكل (1) انتقالات أنموذج التوازن الكلي (AD/AS) المعاصر باستخدام فريضة الزكاة

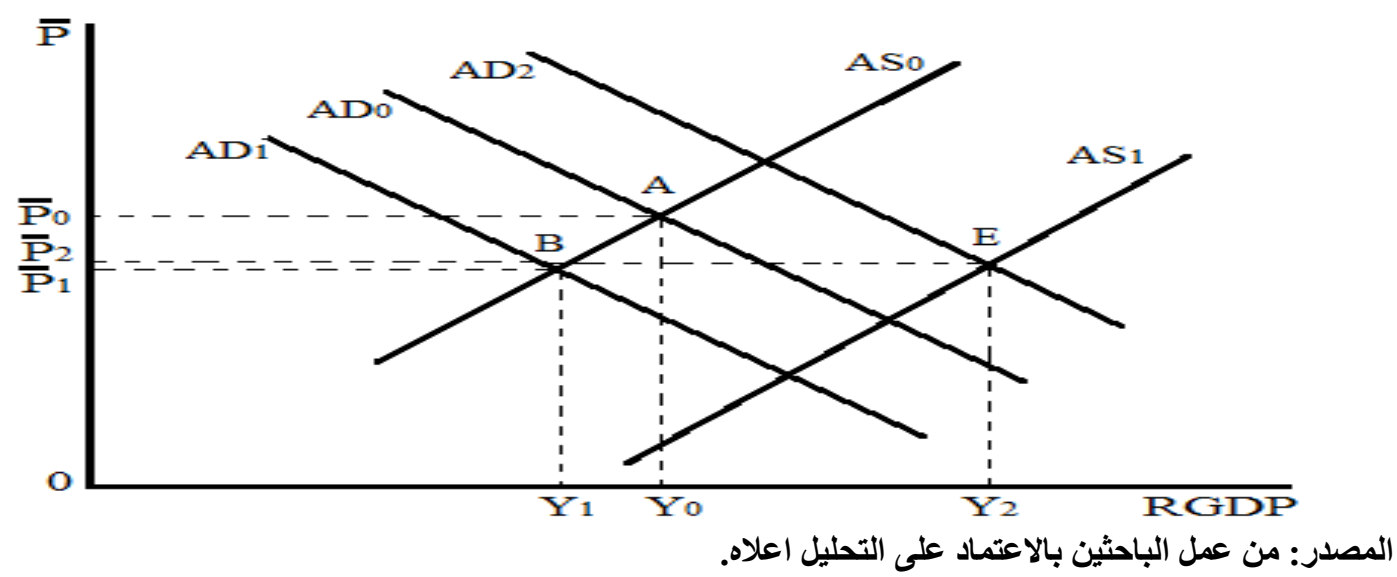

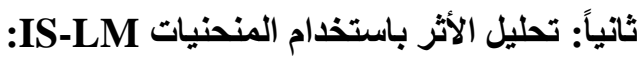

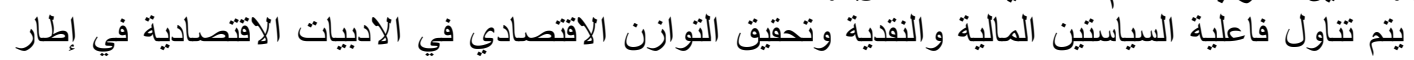

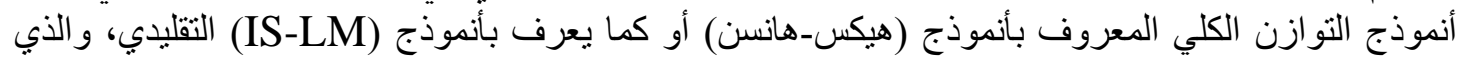

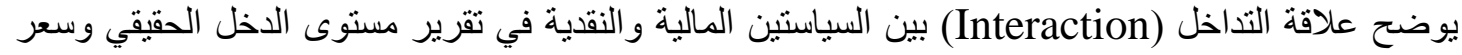
الفائدة وكما موضح في الثكل (2): 
المجلة اللحولية اللملوم الآنسانية والإمتماعية International Journal of Humanities and Social Sciences website:www.ijohss.com Email:editor@ijohss.com غسطس 2020 (14) (لعدا ISSN: $2415-4822$

Volume (14) August 2020

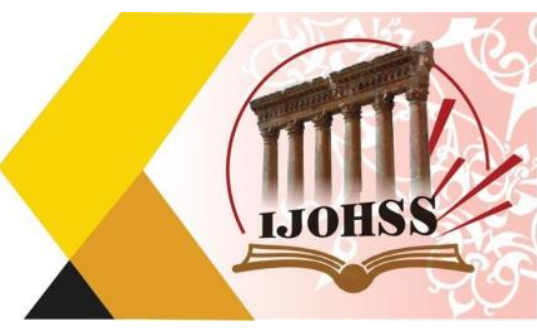

شكل (2) أنموذج التوازن الكلي (IS-LM) التقليدي

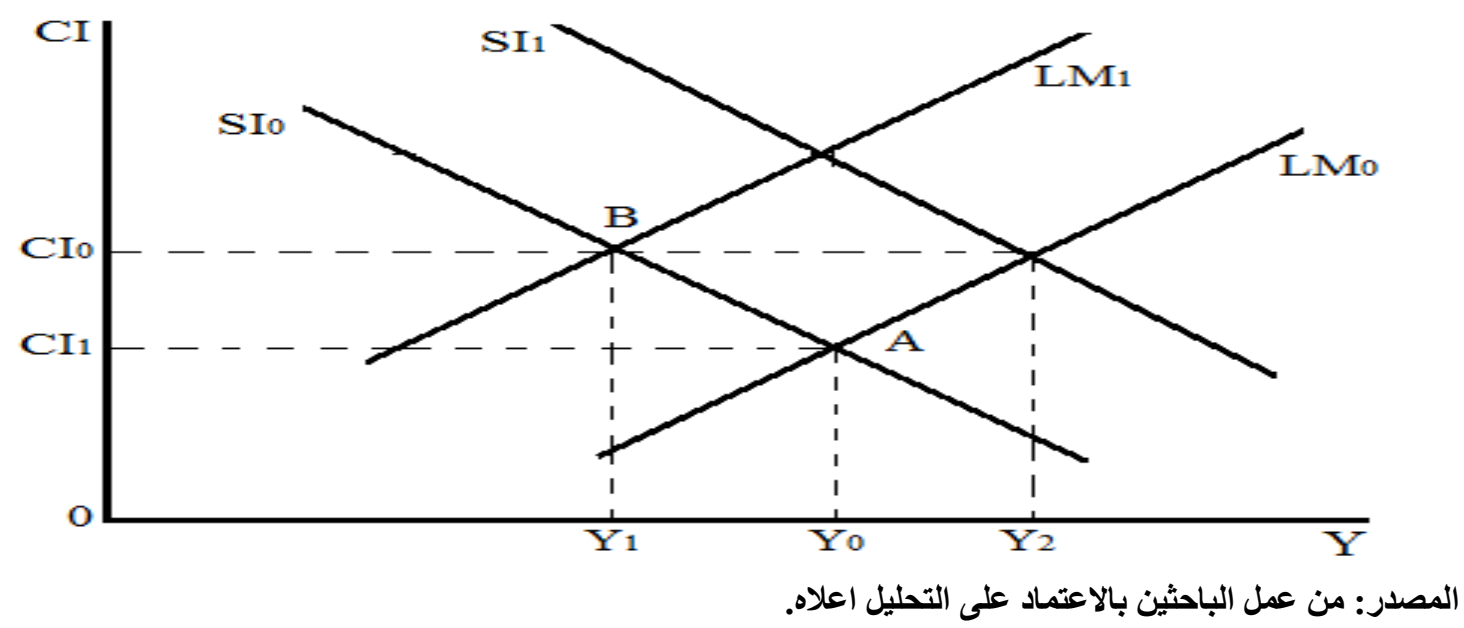

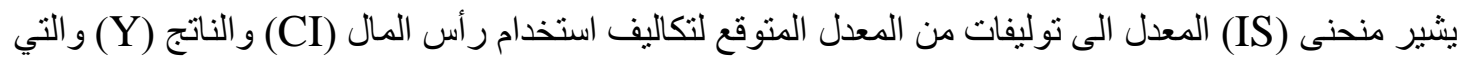

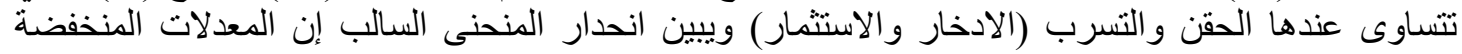

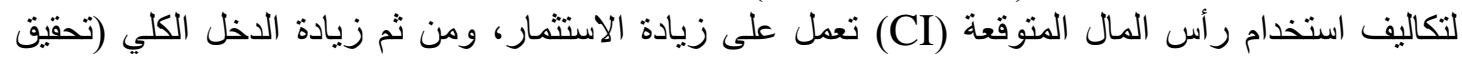
التوازن في السوق الحقيقي)، في حين يشير منحنى (LM) المعدل الى نوليفات من المعدل المتوقع لتكاليف

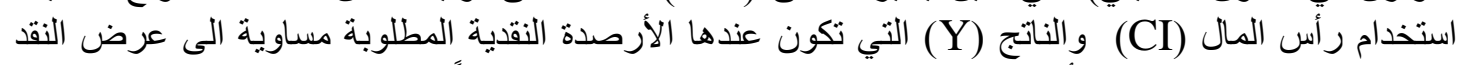

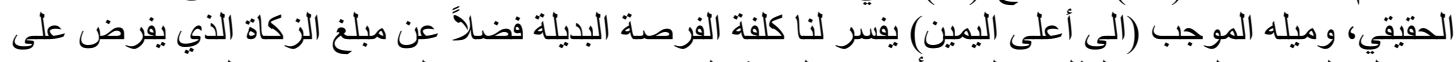

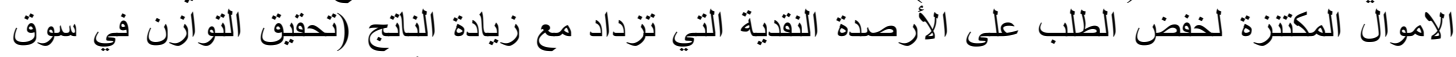
النقود)، و عليه عندما يتقاطع منحنى (IS) المعدل مع منحنى (LM) المعدل ينشأ عنه مستوى تو ازني في سوفي

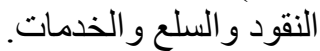

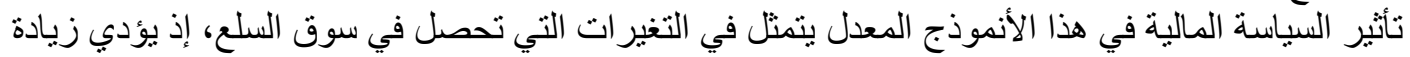

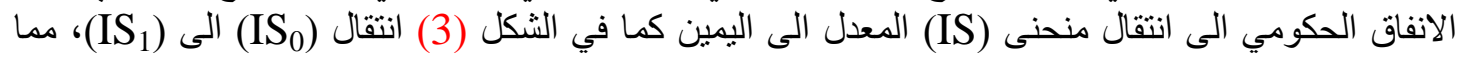

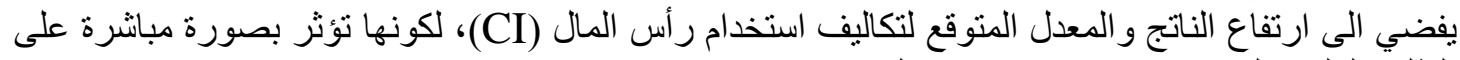

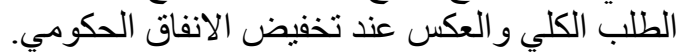

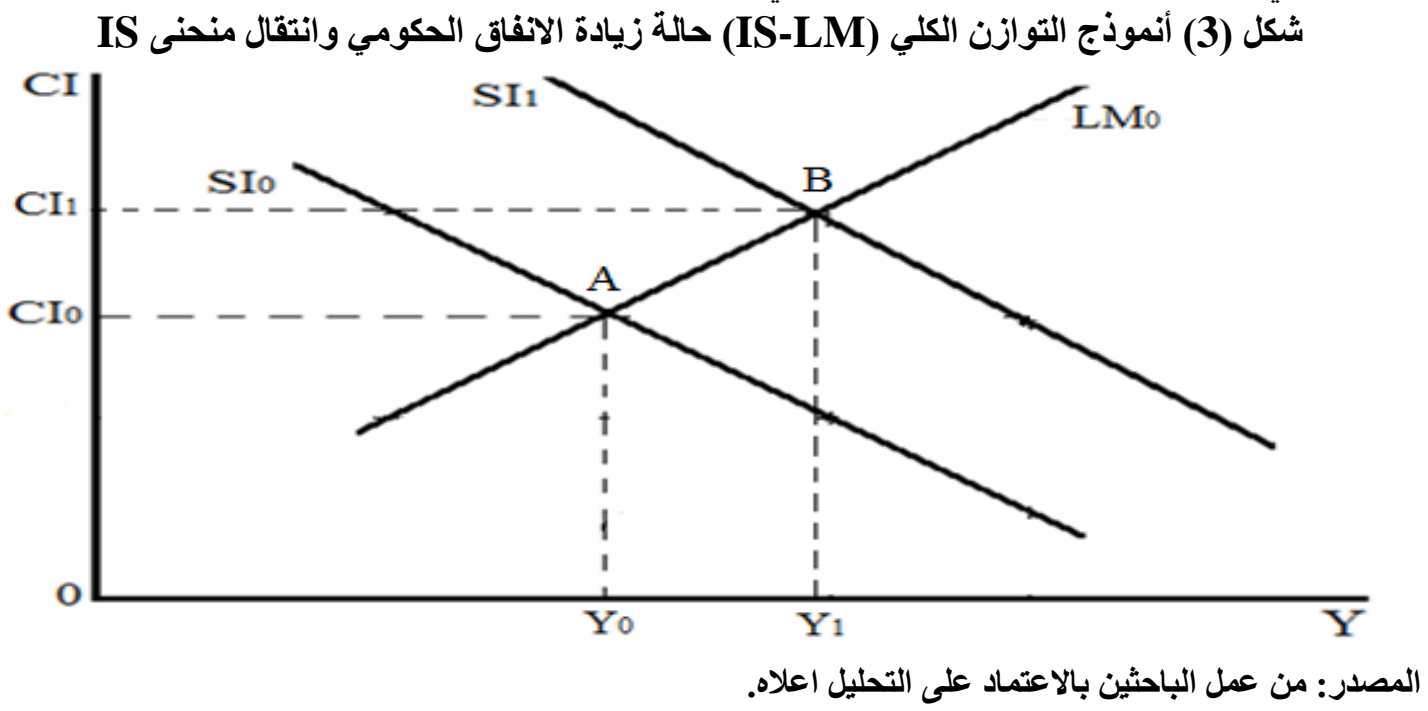


أغسطس 2020

(14) (لعدا

ISSN: $2415-4822$

Volume (14) August 2020

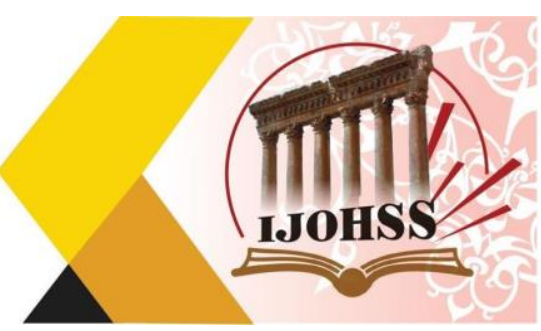

في حين تتمثل السياسة النقدية من خلال تأثثرها في سوق النقود، ففي حال قيام السلطة النقدية باتباع سياسة

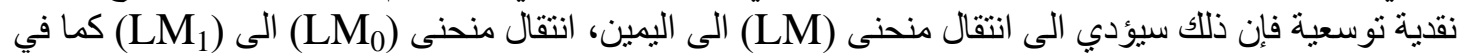

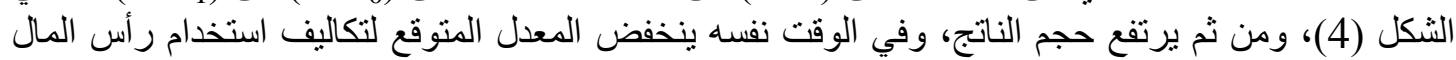

و و العكس عند اتباع سياسة نقدية انكماثية.

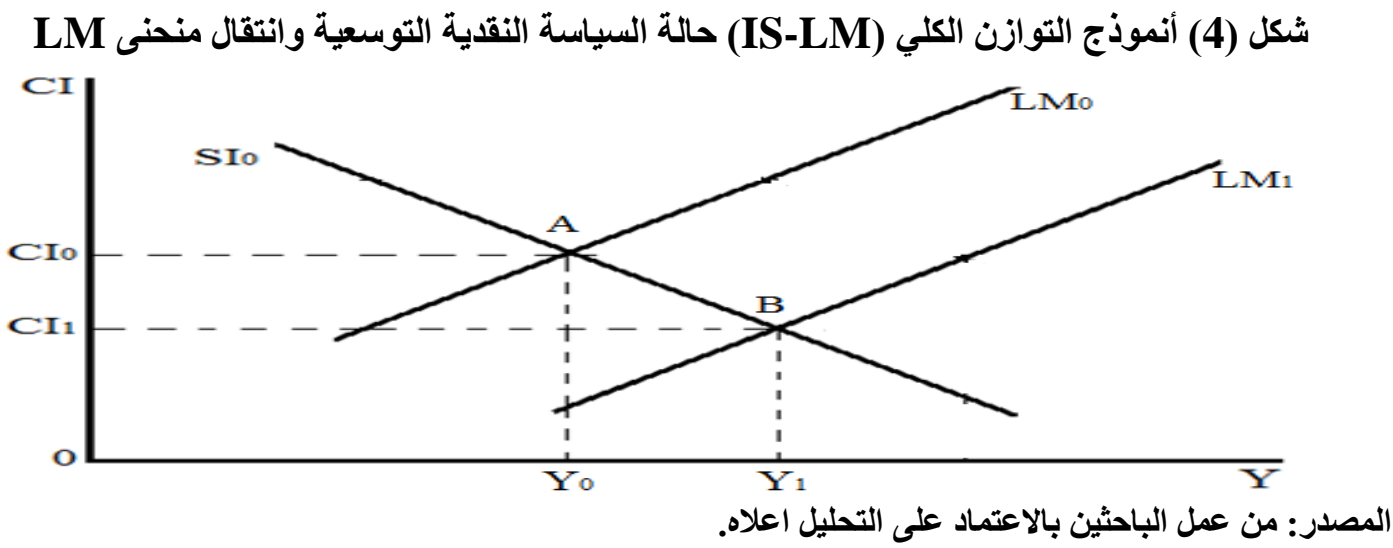

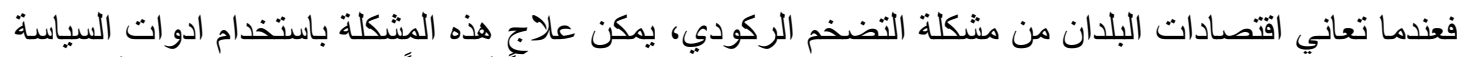

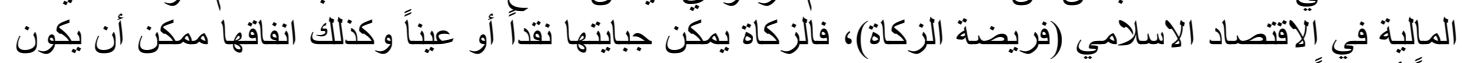
نقاً أو عيناً. ففي حالة تحصيل فريضة الزكاة نقداً فإن ذلك سيؤدي الى انخفاض عرض الني النقد بسبب سحب كميات من النقد

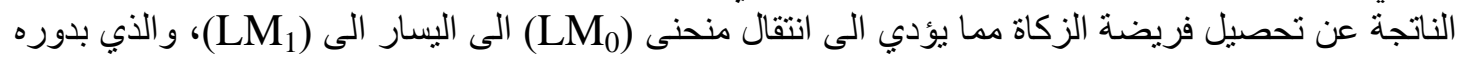

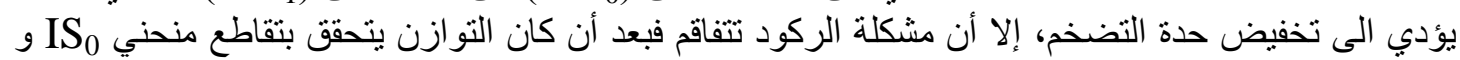

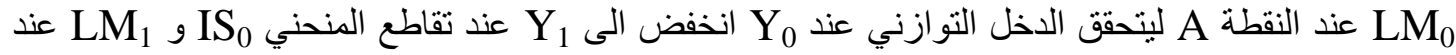
النقطة B. إلا أن انفاق حصيلة فريضة الزكاة في الوقت نفسه الذي تم فيه تحصيل فريضة الزكاة مما يؤدي الى الى

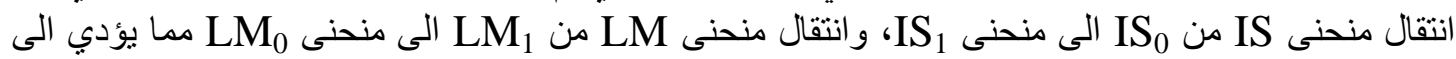
تحقيق نقطة تقاطع جديدة عند منحني التوني

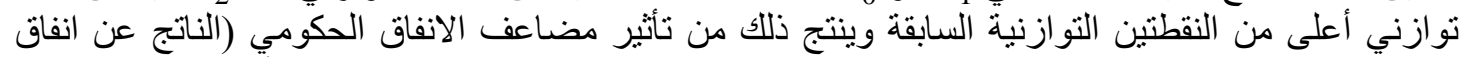

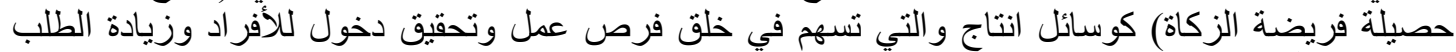

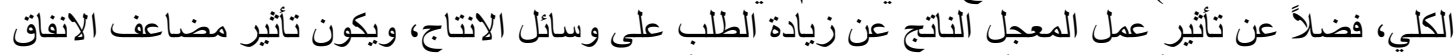

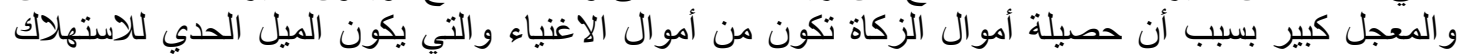

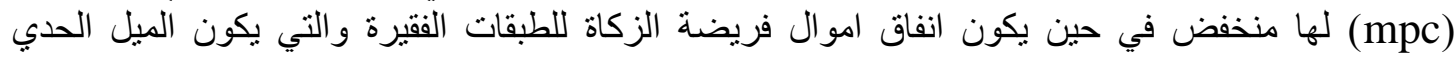

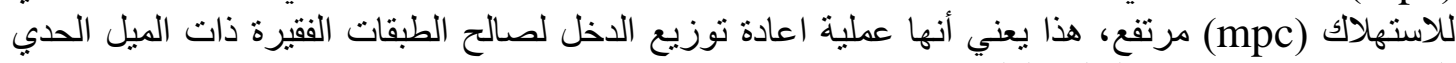
المرتفع و هذا يعني زيادة الطلب الكلي.

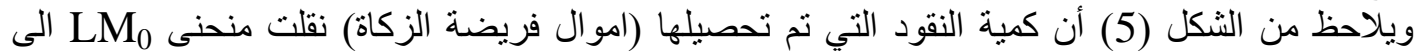

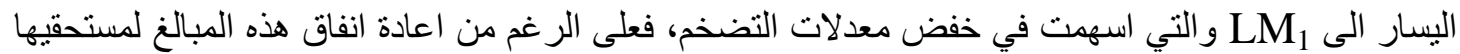

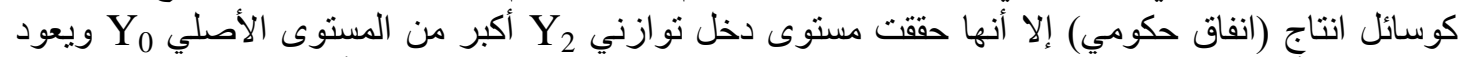

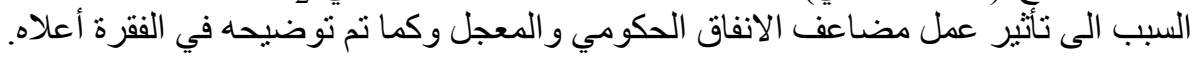




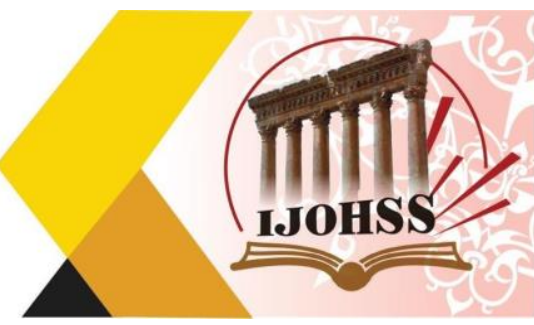

شكل (5) حالة التوازن في أنموذج التوازن الكلي (IS-LM) باستخدام فريضة الزكاة ومعالجة مشكلة التضخم الركودي

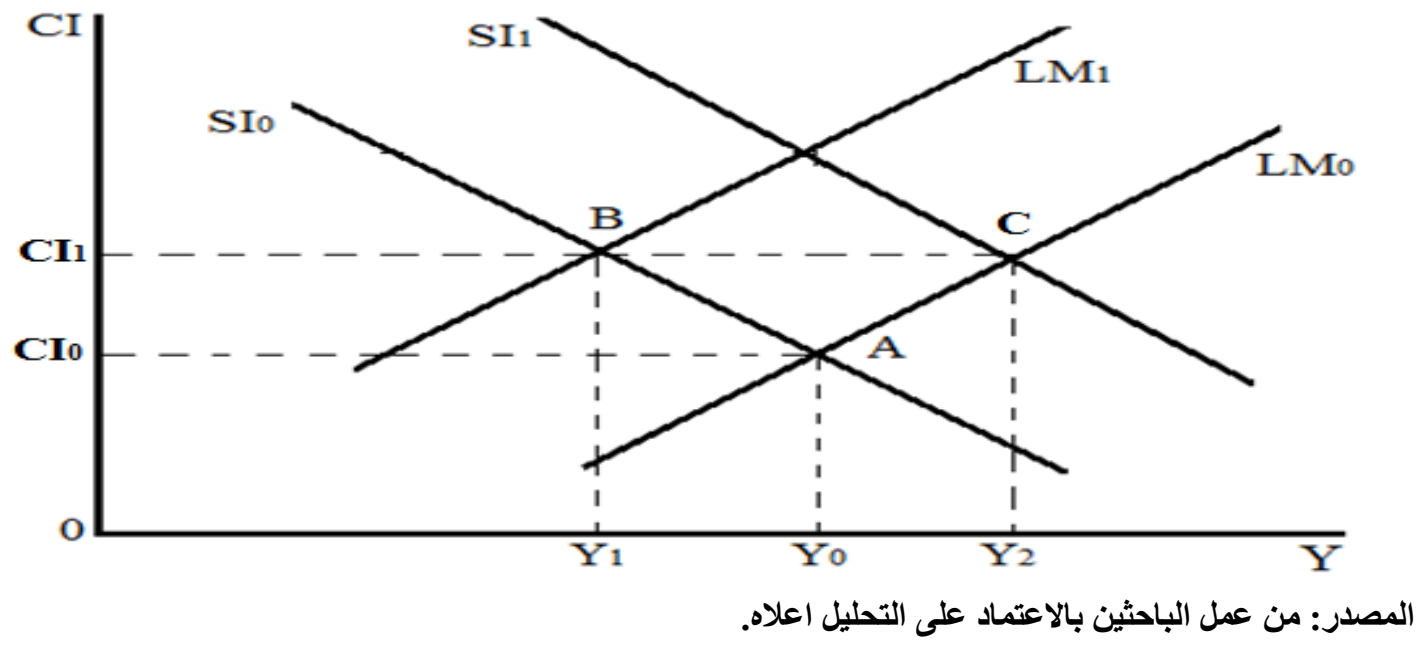

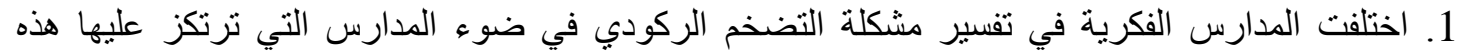

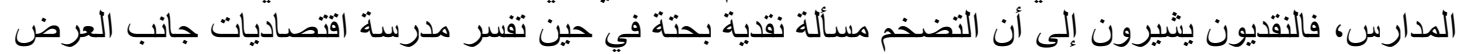

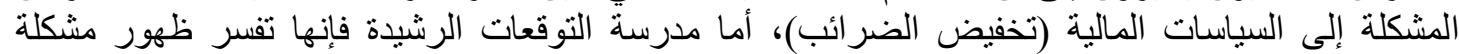

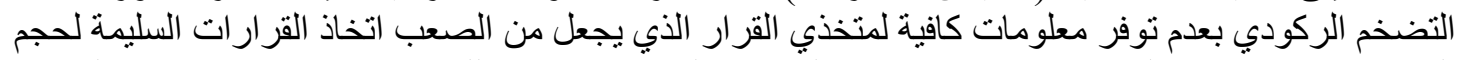

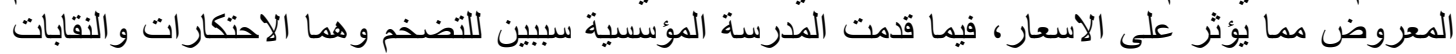

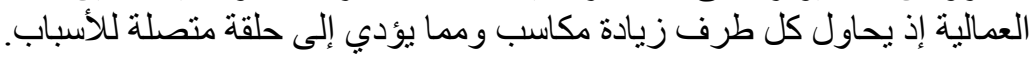

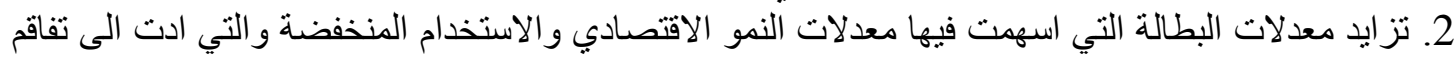
مشكلة التضخم الركودي. 3. يؤدي الخلل في التو ازن بين الطلب الكلي و العرض الكلي إلى ظهور وتفاقم مشكلة التضخم باستمر ار.

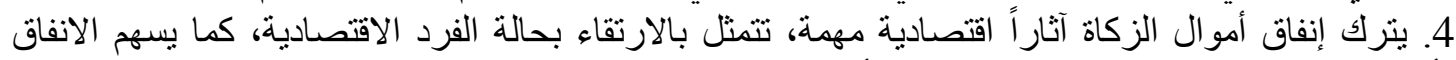

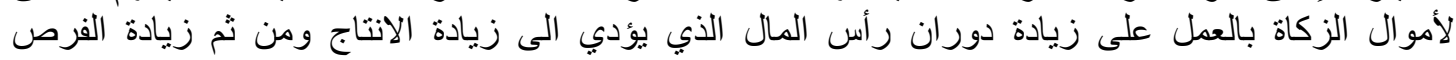

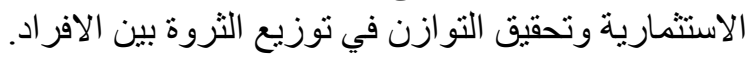

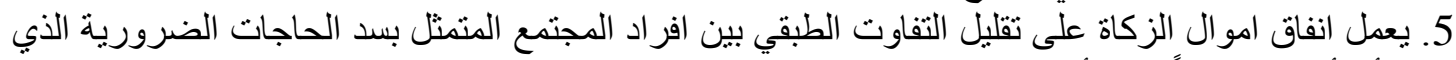
من شأنه أن تخلق جواً من الأمان الزمان.

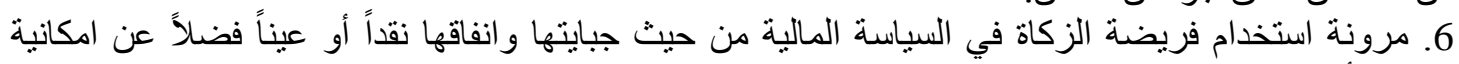

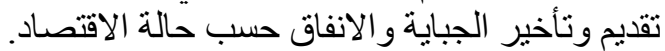
7. فاعلية فريضة الزكاة أحدى أدوات السياسة الألية المالية في الاقتصاد الاسلامي في معالجة العديد من المشكلات الاقتصادية ومنها مشكلة التضخم الركونة الركودي.

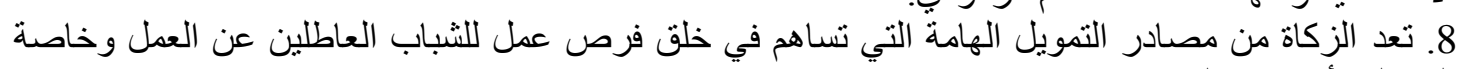
المؤهلين أكاديميا ولكنهم غير قادرين ماديا.

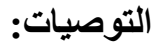

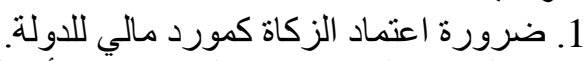

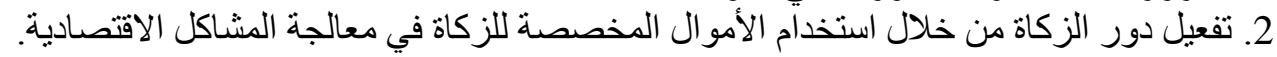
3. استخدام الزكاة كأداة فاعلة في السياسة المالية، ودور ها في تقليل التفاوت بين العرض الكالئ الكلي و الطلب الكلي. 


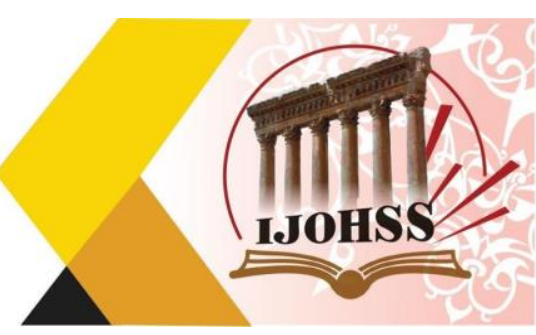

المراجع والمصادر العربية

1. زكي، رمزي، 1985، "الموقف الراهن للجدل حول ظاهرة التضخم الركودي ومدى ملاءمته لتفسير الضغوط التضخمية بالبلاد المتخلفة"، التضخم في العالم العربي، بحوث ومناقثنات اجتماع عقد في الكويت 16-

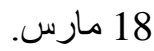
2. ارنولد، دانييل، 1992، تحليل الأزمات الاقتصادية للامس واليوم، ترجمة: د.عبد الأمير شمس الدين، ط1،

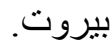
3. سامويلسون، بول، نورد هاوس، ويليام، ماندل، مايكل،2001، الاقتصاد، ترجمة: هشام عبدالله، ط15، الدار

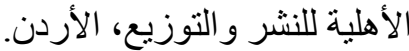

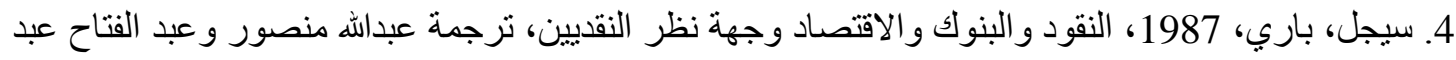
الرحمن، الرياض: داري، دار المريخ للنشر.

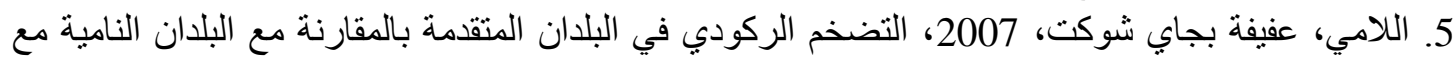

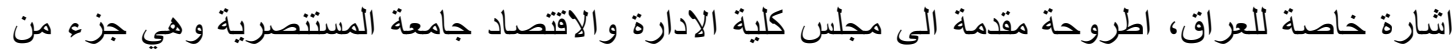
متطلبات نيل درجة الدكتور اه في الاقتصاد. 6. الكفراوي، عوف محمود، 1997، السياسة المالية والنقدية في ظل الاقتصاد الإسلامي، الإسكندرية: مكتبة

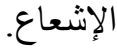

7. الكفر اوي، عوف محمود، 2000، بحوث في الاقتصاد الإسلامي، الإسكندرية: مؤسسة الثقافة الجامعية. 8. حماد، نزيه، 1981، معجم المصطلحات الاقتصادية في لغة الفقهاء، الولايات المتحدية الإندية الأمريكية: المعهد

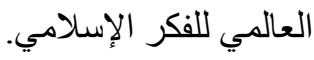

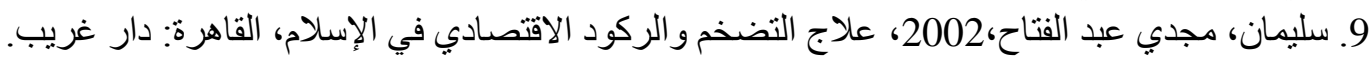
10. رحاحلة، إبر اهيم القاسم، 1999، مالية الدولة الإسلامية، القاهرة: مكتبة مدبولي.

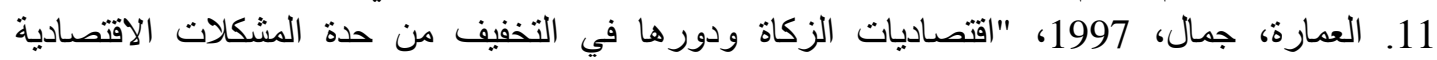

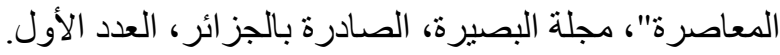

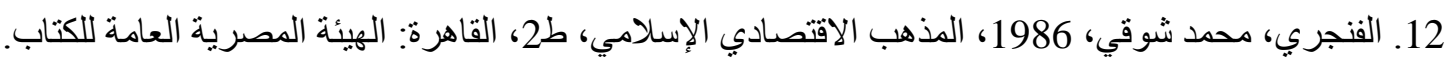

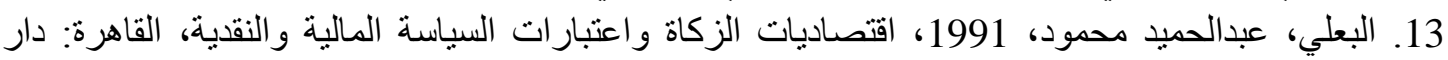
السلام.

14. محمد، قطب إبر اهيم، 1988، السياسة المالية للرسول، القاهرة: الهيئة المصرية العامة للكتاب.

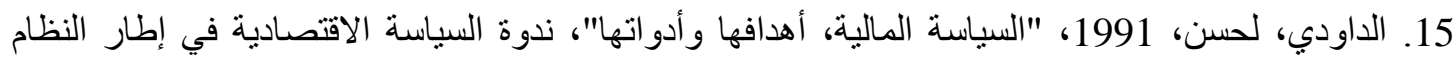
الإسلامي، جدة: البنك الإسلامي للتنمية.

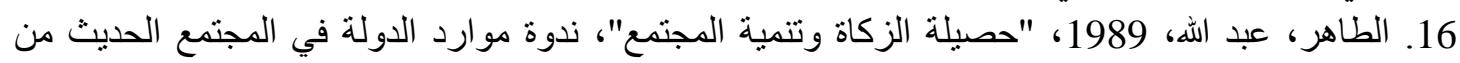
وجهة النظر الإسلامية، القاهرة، البنك الإسلامي للتنمية. 17. العسال، أحمد محمد، و عبد الكريم، فتحي أحمد، 1985، النظة، لإمة الإقتصادي في الإسلام مبادئه و أهدافه، ط7،

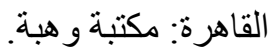

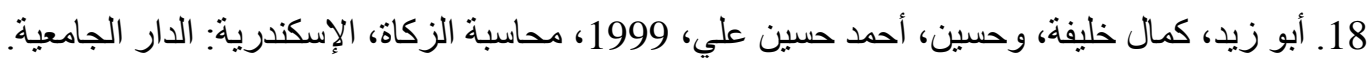

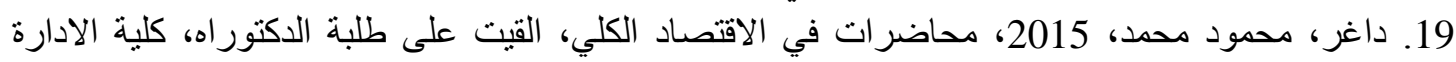

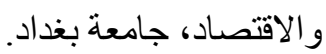




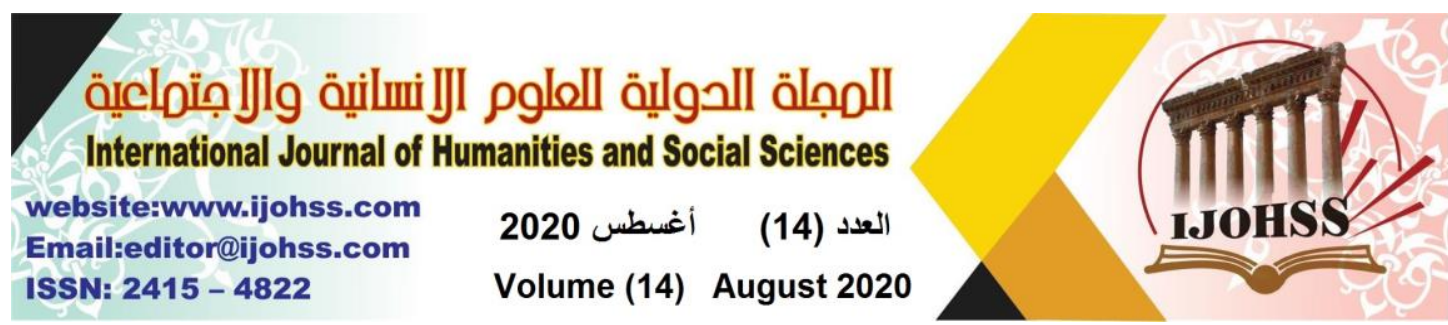

\section{References}

1. Zaki, Ramzi, 1985, "The current position of the controversy over the phenomenon of stagnant inflation and its suitability to explain the inflationary pressures in underdeveloped countries", Inflation in the Arab World, Research and Discussion Meeting held in Kuwait 16-18 March.

2. Arnold, Daniel, 1992, Analysis of Economic Crises Yesterday and Today, translation: Dr. Abdel Amir Shams El-Din, 1st edition, Beirut.

3. Samuelson, Paul, Nord House, William, Mandel, Michael, 2001, Economics, translation: Hisham Abdullah, 15th Edition, Al-Ahlya Publishing and Distribution House, Jordan.

4. Siegel, Barry, 1987, Money, Banking, and Economy: A Critics' Point of View, translated by Abdullah Mansour and Abdel-Fattah Abdel-Rahman, Riyadh: AlMerikh Publishing House.

5. Al-Lami, Afifa Bajai Shawkat, 2007, Stagnant Inflation in Developed Countries Compared to Developing Countries with Special Reference to Iraq, thesis submitted to the Board of the Administration and Economics College of Al-Mustansiriya University, which is part of the requirements for obtaining a $\mathrm{PhD}$ in economics.

6. Al-Kafrawi, Auf Mahmoud, 1997, Monetary and Financial Policy in the Shadow of the Islamic Economy, Alexandria: The Radiation Library.

7. Al-Kafrawi, Ouf Mahmoud, 2000, Research in Islamic Economics, Alexandria: University Culture Foundation.

8. Hammad, Nazih, 1981, A Dictionary of Economic Terms in the Language of Jurists, USA: International Institute for Islamic Thought.

9. Suleiman, Magdi Abdel-Fattah, 2002, Treating Inflation and Economic Stagnation in Islam, Cairo: Dar Gharib.

10. Rahahala, Ibrahim Al-Qasim, 1999, Islamic State Finance, Cairo: Madbouly Library.

11. Architecture, Jamal, 1997, "The Economics of Zakat and its Role in Reducing the Intensity of Contemporary Economic Problems," Al-Insira Magazine, published in Algeria, first issue.

12. Al-Fangary, Mohamed Shawky, 1986, Islamic Economic Doctrine, 2nd edition, Cairo: The Egyptian General Book Authority.

13. Al-Baali, Abdel Hamid Mahmoud, 1991, Zakat Economics and Financial and Monetary Policy Considerations, Cairo: Dar Al Salam.

14. Mohamed, Qutb Ibrahim, 1988, The Messenger's Financial Policy, Cairo: The Egyptian General Book Authority.

15. Al-Daoudi, Lahcen, 1991, "Financial Policy, Its Objectives and Tools", Economic Policy Seminar in the Framework of the Islamic System, Jeddah: The Islamic Development Bank.

16. Al-Taher, Abdullah, 1989, "The Outcome of Zakat and Community Development," Seminar on State Resources in Modern Society from an Islamic Viewpoint, Cairo, the Islamic Development Bank. 


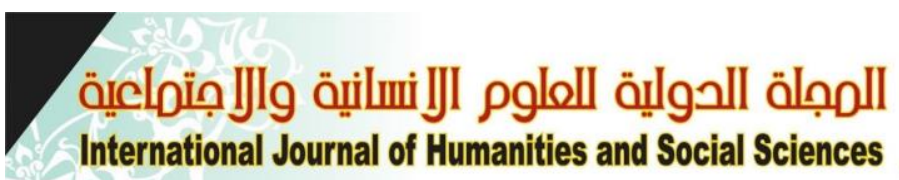
website:www.ijohss.com Email:editor@ijohss.com أغسطس 2020 العدد (14) ISSN: $2415-4822$ Volume (14) August 2020

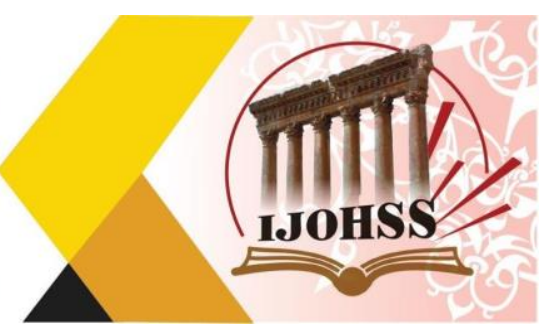

17. Al-Assal, Ahmed Mohamed, and Abdel-Karim, Fathi Ahmed, 1985, The Economic System in Islam, Its Principles and Goals, 7th Edition, Cairo: Wahba Library.

18. Abu Zaid, Kamal Khalifa, and Hussein, Ahmed Hussein Ali, 1999, Zakat Accounting, Alexandria: University House.

19. Dagher, Mahmoud Mohamed, 2015, lectures in Macroeconomics, PhD students, College of Administration and Economics, University of Baghdad.

20. Roberrt ,B,Ekelund,Jr: Robert F.Hert,Ahistory of Economic Theory and Method, Second Edition,1981,pp423-424.

21. Norbert Berthold \& Klaus Grundler ,Stagflation in the world Economy; A Revival? „Julius-Maximilians-University Wurzburg ,April, 2012. 